\title{
P450 OXIDOREDUCTASE DEFICIENCY: ANALYSIS OF MUTATIONS AND \\ POLYMORPHISMS
}

Fabian Burkhard ${ }^{\#}$, Shaheena Parween ${ }^{\#}$, Sameer S Udhane” ,Christa E Flückand Amit V. Pandey*

Division of Pediatric Endocrinology, Department of Pediatrics, University Children's Hospital Bern, and Department of Clinical Research, University of Bern, Switzerland.

Running title: PORD

${ }^{\#}$ These authors contributed equally to the work.

*Address for correspondence:

PD Dr. Amit V Pandey, Pediatric Endocrinology Diabetology and Metabolism, KIKL C837, University Children’s Hospital, Inselspital, Freiburgstrasse 15, 3010 Bern

Switzerland

Phone: +41316329637

Email: amit@pandeylab.org

Key words:Cytochrome P450 oxidoreductase, P450 oxidoreductase deficiency, PORD, Steroid Metabolism, Antley-Bixler syndrome, Disorders of Sexual Development, CYP17A1 


\section{Abstract}

Cytochrome P450 oxidoreductase (POR) is required for metabolic reactions of steroid and drug metabolizing cytochrome P450 proteins located in endoplasmic reticulum. Mutations in POR cause a complex set of disorders resembling combined deficiencies of multiple steroid metabolizing enzymes. The P450 oxidoreductase deficiency (PORD) was first reported in patients with symptoms of defects in steroidogenic cytochrome P450 enzymes and ambiguous genitalia and bone malformation features resembling Antley-Bixler syndrome. POR is now classified as a separate andrare form of congenital adrenal hyperplasia (CAH), which may cause disorder of sexual development (DSD). Since the initial description of PORD in 2004, a large number of POR mutations and polymorphisms have been described. In this report we have performed computational analysis ofmutations and polymorphisms in POR linked to metabolism of steroids and xenobiotics and pathology of PORD from the reported cases. The mutations in POR that were identified in patients with disruption of steroidogenesisalso have severe effects on cytochrome P450 proteins involved in metabolism of drugs. Different variations in POR showa range of diverse effects on different partner proteins that are often linked to the location of the particular variants. The variations in POR that cause defective binding of co-factors always have damaging effects on all partner proteins, while the mutations causing subtle structural changes may lead to altered interaction with partner proteins and the overall effect may be different for each individual partner.Computational analysis of available sequencing data and mutation analysis shows that Japanese (R457H), Caucasian (A287P) and Turkish (399401)populations can be linked to unique founder mutations. Other mutations identified so far were identified as rare alleles or in single isolated reports. The common polymorphism of POR is the variant $\mathrm{A} 503 \mathrm{~V}$ which can be foundin about $27 \%$ of alleles in general population but there are remarkable differences among different sub populations. 


\section{Introduction}

Cytochrome P450 reductase (POR)(OMIM: *124015, HNGC:9208) is key enzyme involved in metabolism of drugs and steroid hormones (Figure 1)[1-3]. All cytochrome P450enzymes located in the endoplasmic reticulum get electrons for their catalytic activities from the co-factor nicotinamide adenine dinucleotide phosphate (NADPH) through POR[1, 4, 5].The gene of POR humans contains one non-coding exon and 15 protein-coding exons which code for a membrane bound protein (NCBI: NP_000932, UniProt: P16435) containing 680 amino acids.

The defect in POR known as cytochrome P450 oxidoreductase deficiency (PORD); (OMIM:613571,OMIM: 201750) is arare form of congenital adrenal hyperplasia (CAH)[2, 68]. In the patients with disorders of steroid metabolism, sequencing of genes for steroid metabolizing cytochrome P450 enzymes led to identification of genetic defects in CYP17A1, CYP19A1, CYP21A2 and many other targets. However, many cases remained unresolved and a correct genetic diagnosis could not be made.Of these, a particular category of patients had steroid hormone profiles indicative of combined defects in 21-hydroxylase and 17-hydroxylase genes and fit the profile of the bone malformation disorder Antley-Bixler Syndrome[9]. Sequencing of genes for CYP21A2 and CYP17A1 did not provide a diagnosis and possibility of a defect in one of the redox partnerslike cytochrome b5 or cytochrome POR was postulated but no studies were carried out to check this hypothesis[10]. Kelley et al evaluated the role of CYP51A1 in a patient with ambiguous genitalia without known mutationsin the fibroblast growth factor receptor 2 (FGFR2) and found indications of CYP51A1 deficiency [11], but no mutations in CYP51A1 were found[11]. In 2003 analysis of the gene for POR in a 46,XX Japanesegirl who had aprofile of 21 and 17-hydroxylase deficienciesprovided the genetic proof for a defect in POR[6]. The severity of effects on the POR protein was confirmed with enzymatic analysis by recreating the mutations found in patients in recombinant forms by expressing the proteins in yeast as well as bacteria and testing the activities of mutant proteins 
with CYP17A1 hydroxylations, cytochrome c reduction and NADPH oxidation assays. This analysiswas reported in 2004 established the characterization of PORD as arare form of CAH due tomutations in POR that disruptthe activities of steroid metabolizing enzymes located in the endoplasmic reticulum like CYP17A1, CYP19A1, CYP21A2, and CYP51A1 [6-8] (Figure 1). After the publication of initial report, a larger cohort of patients were analyzed and it became clear that malformation of the skeleton like clover leaf head, that were found in some patients with ABS who also had ambiguous external genitalia and abnormal metabolism of steroids, were due to PORD[12]. Based on this, PORD can be considered a separate disorder of metabolism, independent of Antely-Bixler Syndrome[12]. Steroid metabolome data from a large number of patients with diagnosis of PORD have been studied in the last decade and show that PORD affects biosynthesis of steroid hormones in both the adrenal cortex and the gonads[1215]. The dual targets of androgen and estrogen metabolismmay lead to ambiguous external genitals at birth in both male and female. During fetal development the lack of androgens (testosterone and dihydrotestosterone)causes the development of female external genital organs[16]. In presence of testosterone and dihydrotestosterone, downstream signaling events cause developmental changes leading to the formation of male external genitalia.

In humans the androgen biosynthesisbeginsby metabolism of pregnenolone to 17hydroxypregnenolone (17-OHPreg) and further on todehydroepiandrosterone (DHEA) by two different activities of CYP17A1 in the adrenal gland[2, 17] (Figure 2). These CYP17A1 mediated reactions require electron transport from NADPH via POR[1, 17]. Similarly CYP19A1 is involved in formation of estrogens and requires POR for its catalytic activities[13, 14, 18]. Therefore, a defect in POR may lead to disruption of both androgen and estrogen metabolism and affect sexual developmentin both male and female[19, 20]. Although the discovery of PORD provided an explanation for the genetic basis of mixed oxidase deficiency in many cases, there remain a large number of patients without exact genetic diagnosis, indicating that many 
other genes may be involved and similar phenotypes may be created by multigene disorders[16].

Recently mutations in two aldo-keto reductase enzymes the AKR1C2 (OMIM: 614279) and its homologue, AKR1C4 (OMIM: 600451) have been reported[21]. This discovery has now postulated two differentpathways for androgen production in the fetal testisthat wouldregulate the process ofmale/female sexual differentiation[16, 21-23]. POR is involved in both pathways[1, 22] (Figure 2).Many variations inPOR responsible for several hundred amino acid alterations have been found in sequencing studies across the world[13, 20, 24-37].Here we are analyzingthe information on disease related as well as naturally occurring variants of the POR gene. In addition, we have analyzed the reports of PORD for clinical and biochemical analysis as well as effect of variations on in vitro activities with several redox partners. We then analyzed latest available information on sequence variations in POR from genomic databases that catalogue the result of large studies like 1000 genomes project.

\section{Materials and Methods}

2.1 Sequence alignments:The POR protein sequences were obtained from NCBI protein database and aligned usingwith CLC Protein Workbench (CLC Bio, Aarhus, Denmark). In the first round we used sequences of Homo sapiens (NCBI: NP_000932.3), Rattus norvegicus (NCBI: NP_113764.1), Mus musculus (NCBI: NP_032924.1), Bos taurus (NCBI: NP_001030467.1), Canis familiaris (NCBI: XP_858049.1), Gallus gallus (NCBI: XP_415768.2), Drosophila melanogaster (NCBI: NP_477158.1), Anopheles gambie (NCBI: XP_301593.4), Danio rerio (NCBI: NP_001030154.1), Caenorhabditis elegens (NCBI: NP_498103.1), Arabidopsis thaliana (NCBI: NP_194183.1), Magnaporthe grisea (NCBI: XP_367192.1), Neurospora crassa (NCBI: XP_330391.1), Schizosaccharomyces pombe (NCBI: NP_596046.1), Saccharomyces cerevisiae (NCBI: NP_011908.1), Eremothecium gossypii (NCBI: NP_982421.1) and Kluyveromyces lactis (NCBI: XP_453451.1) sequences in our alignment.

2.2 3D protein models - The 3D structural model of mutant POR (NCBI NP_000932) was built using the three dimensional crystal structure (3QE2) as template. Model building was performed with programs YASARA [38] and WHATIF [39]. A screening of rotamer libraries was used to minimize stearic clashes with the neighboring residues that resulted from the substitution of amino acids. Side chains were optimized by molecular dynamic (MD) simulations. The final model was refined by a 1000 ps (MD) simulation using AMBER 2003 force field and checked with the programs WHAT_CHECK [40], WHATIF [39], Verify3D [41, 42], and Ramachandran plot analysis [43, 44]. Structural properties of the proteins was calculated by YASARA and WHATIF and general protein parameters were calculated with Expasy protein tools (www.expasy.ch). Coordinates of two rat POR crystal structures (PDB\# 1JA1, 1AMO) [45-47] were also used for comparative studies. Structure models were depicted with Pymol (www.pymol.org) and rendered as ray traced images with POVRAY (www.povray.org). 
2.3 Molecular Dynamics simulation for model refinement - The MD simulations were performed using AMBER03 force field [14, 38]. The simulation cell was filled with water, $\mathrm{pH}$ was fixed to 7.4 and the AMBER03 [48] electrostatic potentials were evaluated for water molecules in the simulation cell and adjusted by addition of sodium and chloride ions. The final MD simulations were then run with AMBER03 force field at 298K, $0.9 \% \mathrm{NaCl}$ and $\mathrm{pH}$ 7.4 for 1000 ps to refine the model. Best models were selected for analysis and evaluation of the effect of mutations.

2.4 Predicting the Effect of on Protein Stability Using site directed mutator (SDM) - The SDM tool [49] described by Topham et al [50], was used for predicting the effect of POR mutants. SDM software uses environment-specific substitution frequencies within homologous protein families to calculate a stability score. The mutant structures used for analysis was generated using the built in program ANDANTE [51]. SDM provides a pseudo delta G score for stability prediction and also a potential impact of mutation for causing disease.

2.5 Analysis of evolutionary conservation of amino acids in POR: We used ConSurf analysis to study the evolutionary conservation of amino acids in POR based on structural and phylogenetic relationships between the sequences from different species[52, 53]. All the POR sequences in Uniprot database were searched and 150 best quality sequences based on three rounds of iterated Phi-BLAST search were kept for further analysis.

2.6 POR activity comparison:Data on in vitro activities of POR variants with different partner proteins were compiled from published assays from us as well as other investigators.

2.7 Analysis of POR allele frequencies from genome sequencing studies:Frequencies from 1000 Genomes [54], NHLBI Exome Sequencing Project (NHLBI Exome Sequencing Project, 2016), SNP500CANCER, POR-Miller [33], JBIC-allele [55] and EGP SNPs (NIEHS Environmental Genome Project, 2016) were collected and assigned to the main categories of the 1000 Genomes project. Pacific Islanders (PAC) was created as a subcategory of East Asians (EAS).

\section{Results and Discussion}

\subsection{Clinical profile of PORD}

The PORD has a broad clinical spectrum as we have described previously[1, 2]. In thefirst published report about PORD, out of the four unrelated patients, three patients of either 46,XX or 46,XY chromosomal sex had ambiguous genitalia and skeletal malformations characteristic of Antley Bixler syndrome (OMIM ABS1-201750; ABS-207410), and one young woman only had primary amenorrhea and mild arterial hypertension [6]. In the next report with larger number of patients collected from across the world[56]two unrelated 46,XX girls showed signs 
of ambiguous external genitalia and symptoms resembling a milder form ofABS at birth, but the younger 46,XY brother of one of these patients normal male external genitals at birth and there were no signs of malformations in bone structure, even with a steroid profile that was abnormal and same POR mutations were present in all cases. Virilization of mothers during pregnancy seems like a clinical, though not an obligate characteristic of PORD, and is similar to pregnancies with fetuses with a defect in aromatase (CYP19A1). Currently more than 130 patients with PORD have been reported in different publications from multiple laboratories and these cases show that there is wide range of phenotypic features in PORD (Table 1) [6, 12, 13, 29, 31, 56-64].

Three investigations have attempted to perform genotype-phenotype correlations of patients with PORD to establish any potential similarities in clinical features [12, 29, 60]. In the first report Huang et al found POR mutations in 19/19 patients with both 46,XX and 46,XY disorder of sexual development (DSD) as well as disruption in activities of steroid metabolizing enzymes among a group of 32 patients who had physiological features resembling ABS and/or disruption in biosynthesis of steroid hormones that was indicative of deficiencies in both 17 and, 21-hydroxylase enzymes[12]. Out of 32 the 9 out of 12 patients with ABS who also had normal external genitalia and normal profile of steroid biosynthesis, fibroblast growth factor receptors 2 or 3 (FGFR2,-3) genes were found to have mutations. Huang et al hypothesized that patients with ABS symptoms who have normal genitalia and no apparent defect in steroid biosynthesis can be categorized as a separate group. Rest of the patients who have mutations in POR, defects in steroid metabolism and signs of ambiguous external genitals can be assigned to PORD [12]. In earlier reports ABS patients who had no genital development defectswere found to carry mutations in the FGFR2[65]. In the second larger study, Fukami et al characterized 35 patients from Japan who had symptoms of PORD into three differentgroups: group A was homozygote for POR mutation R457H (common in Japan); group B had compound heterozygote presence of 
POR mutation $\mathrm{R} 457 \mathrm{H}$ in combination with a mutation that caused loss of function; and $\mathrm{C}$ as those patients with all other mutations [60]. Group B had highest association with anomalies associated with ABS. The signs of DSD were higher in the 46,XX than in the 46,XY individuals. Maternal virilization during pregnancy was seen with equal frequency in both A and B groups. In both A and B group, an abnormal pubertal development was found in all PORD individuals who were 46,XX, while in 46,XY individuals it was variable in all groups. Presence of polycystic ovaries was observed in both pre- and post-pubertal girls in equal ratios among both $\mathrm{A}$ and $\mathrm{B}$ group. In the third study Krone et al investigated 30 individuals who were mainly of Caucasian origin from 11 different countries and formulated a scale for categorizing malformations in skeletal development[29]. In this group, the previously known common mutation in Caucasian population, A287P,was present with highest frequency (43\%), and was present in homozygote state in six of these patients (20\%). Krone et al also proposed five diagnostic ratios for detecting PORD by measurements of urine steroids. A change in all five diagnostic ratios was found in 16 out of 23 patients, while rest of the patients had a difference in four out of five ratios. The ACTH stimulation test detected adrenal insufficiency twenty four out of twenty seven patients. However, there was no link to glucocorticoid deficiency with POR mutations. Most of the subjects under investigation (70\%) hadDSD symptoms at birth; 83\% for 46,XX and 58\% for 46,XY DSD. For the homozygote state of A287P all 46,XX subjects had DSD and all 46,XY subjects were found with normal male external genitals. Krone et al also confirmed the findings of severe malformation in skeletal development by Fukami et al[60] in patients with compound heterozygote state of POR where a loss of function mutation was located on one allele[29].Those DSD patients who were 46,XY has higher scores for skeletal malformations which suggested an effect on steroid biosynthesis and bone development. Patients who were homozygote for POR mutation A287P had phenotypic variabilities that ranged from mild to moderate symptoms for ABS. One can assume that multiple other genes may contribute to outcome of PORD and effects may vary in different patients. 
Our current analysis of more than 130 reported cases of PORD (Table 1) an interruption of adrenal steroid production is always present which may lead to ambiguous external genitals in both sexes at birth but the incidence is higher in females. Most patients with a diagnosis of PORD show signs of skeletal malformations that are similar to ABS symptoms. It is possible that a 'minimal' manifestation of late PORD can happen without any signs of skeletal or genital defects. In these cases a disruption in steroid metabolism is still present and that may affect puberty, lead to infertility and a latent form of adrenal insufficiency.

\subsection{Clinical diagnosis of PORD from steroid measurements and biochemical analysis.}

The biochemical signatures of PORD have beenknown for quite some time even before the exact cause of PORD by mutations in POR became known[9, 66]. Analysis of urine steroids in patients with PORD indicateda defect in both CYP17A1 and CYP21A2 activities[2, 6, 9]. Identification of PORD can be done during neonatal screening or from regular biochemical analysis that showsa mild to moderate increase in serum $17 \mathrm{OH}$ progesterone. However, this can also bemistaken for a defect in CYP21A2 [58]. In PORD, baseline serum ACTH and cortisol are usually found to be normal, and ACTH stimulation does not produce an adequate increase in cortisol production. Sex steroids and their precursors are typically low or low-normal in plasma (as in case of CYP17A1 deficiency). However, serum progesterone, corticosterone, 18OH corticosterone,11-deoxycorticosterone (DOC),18OH DOC, and 21-deoxycortisol are usually found elevated and basal values for renin and aldosterone are normal [6]. Due to a very complex effect on steroid metabolism it is preferable to diagnose PORD by performing mass spectroscopy analysis of urine and blood samples [9, 66]. Usingspot and 24h urine samples the specific steroid metabolic profile of PORD has been performed bygas chromatography/mass spectrometry methods (GC/MS)[9, 29, 57-61, 67, 68]. NilsKrone has described diagnostic ratios of urine metabolites which are helpful in the diagnosis of PORD by GC/MS (Table 2) [29, 68]. 
In a recent study using these ratios for diagnosis, 20 out of 23 (87\%) genetically proven PORD patients were positive for 4 or even 5 out of 5 of these diagnostic ratios [29] confirming this as an excellent diagnostic tool which can be used in early stage before taking up genetic studies. However, confirmation of PORD needs to be done by genetic analysis of POR gene.

Prenatal diagnosis of PORD could be done from the urine or amniotic fluid of the mother [69]. The urine steroid profile of a mother carrying a fetus with PORD is characteristic for low estriol but increased epiallopregnanediol disulfate (metabolite of pregnenolone), and increased androsterone and its precursor $17 \alpha$-hydroxyallopregnanolone [69] (both of these are $5 \alpha$ reduced metabolites in the alternative pathway for the production of dihydrotestosterone (Figure 2) [70]). The androsterone/etiocholanolone $(5 \alpha / 5 \beta \quad$ epimers $)$ ratio and $17 \alpha$ hydroxyallopregnanolone/17-hydroxypregnenonone ratios are also elevated [61, 69]. This suggests that in case of PORD the biosynthesis of androgens shifts from the classic pathway to the alternative pathway. This switch in the steroid production may cause virilization in some 46,XX fetuses and some mothers may also be affected during the pregnancy. Selective inhibition of aromatase activities by certain POR mutants may also cause maternal virilization by androgens produced from male fetuses. In cases of aromatase deficiency the urine steroid profile of mothersshows lower levels of estriol and the metabolites of $16 \alpha$-hydroxyandrostenedione (in PORD these are normal) are found elevated[69].

\subsection{PORD and skeletal malformations}

A large percentage of patients with PORD show skeletal malformations [71] (Table 1). The bone malformations in PORD resemble ABS, a disorder reported in 1975[72]. The ABS cases have a distinct bone malformation phenotype which is characterized by midface hypoplasia, radiohumeral or radioulnar synostosis,craniosynostosis, , bowing of the femora, arachnodactyly, and joint contractures [73-75]. About half the ABS patients have genital anomalies, which is not 
seen in otherforms of craniosynostosis syndromes, $[65,75]$. The ABS patients who have genital anomalies were found to have mutations in POR and no mutations in FGFR2 were found[12, $65]$.

The pathogenesis underlying the skeletal phenotype in PORD has recently been elucidated. Multiple links point to a potential role for POR and biosynthesis of cholesterol in bone development. The cholesterol biosynthesis depends on squalene epoxidase, a non-P450 enzyme, and 14 $\alpha$-demethylase (CYP51) which requires POR for electron transfer [76, 77]. Second, human disorders of cholesterol biosynthesis such as the Smith-Lemli-Opitz syndrome, which is caused by mutations in the gene for 7-dehydrocholesterol reductase, can cause skeletal anomalies. Third, cholesterol is required for normal activity and signal transduction by hedgehog proteins, which are crucial for the regulation of growth, morphogenesis and bone formation in embryogenesis [78]. Aguilar et al have reported that POR knockdown in rat chondrocytes induced apoptosis and resulted in decreased levels of cholesterol [79]. Indian hedgehog, which is involved in regulation of chondrogenesis was reduced upon POR knockdown and recovered again upon cholesterol supplementation [79]. This suggests that the bone malformations associated with POR deficiency may be due to the reduction of cholesterol causing lower Indian hedgehog expression in chondrocytes [79]. In addition, retinoic acid seems to play an important role in the development of skeletal malformations in PORD. Inappropriate levels (excess or deficiency) of retinoic acid can cause a wide range of limb malformations [80-82]. Retinoic acid is metabolized by microsomal CYP26 proteins, which depend on POR for electron transfer. Reducing retinoic acid in the diet of pregnant mice carrying POR knockout pups partially ameliorated their phenotype [82] suggesting a role for retinoic acid toxicity in bone malformations of PORD. In line with these findings, gene expression analysis of conditional limb POR knockout mice recently confirmed that POR deletion leads to excess retinoic acid and impaired cholesterol metabolism [83]. Aberrant 
retinoic acid metabolism due to decreased CYP26 activity was also suggested in PORD patients who were found to have elevated plasma all-trans retinoic acid levels [84].Recently described human null and hypomorphic mutations in the CYP26B1 gene for retinoic acid degradation that are present with skeletal and craniofacial malformationsmatch the phenotype seen in PORD[85].

\subsection{Impact of PORD on metabolism of steroids.}

PORD was first identified as a rare form of CAH and a disorder of sexual development caused by alteredactivities of cytochrome P450 enzymes involved in metabolism of steroid hormones[6, 8]. When the identification of POR variants in normal human population in larger sequencing studies were reported, several studies looked at the effects of many POR variants on the activities of three cytochrome P450 enzymes located in endoplasmic reticulum that are responsible for major reactions in steroid biosynthesis (CYP17A1, CYP19A1 and CYP21A2)[6, 12, 14, 15]. A large number of POR mutations or polymorphisms [12, 13]have been studied and the impact of these variations on structure and function of POR has been described[1, 86].

SeveralPOR mutations that were found in patients are located in the co-factor binding sites and all of these result in severe cases of PORD. The variation A115V was found in patients [33]and has shownenzymatic activities that were similar to WT in the CYP17A1 assays. The T142A mutation causes a change in the FMN binding site, however the effect on several P450 activities are milder[12]. The Q153R mutation causes a change in redox partner binding site,and showed reduced activity in CYP17A1 assays but the CYP19A1 activities were almost double of the WT(Table 3)[12]. Another mutation in the FMN binding domain is G188_V191dup that was found in a Canadian XY patient who hadindications of reduced 17-, 21-hydroxylase activity but enzymatic analysis with recombinant proteins have not been performed[29]. The most common variant in POR in European population is A287P [12]. The A287P had 20-40\% of the WT activityenzymatic assays of CYP17A1 (Table 3) but any serious impact on CYP19A1 activity 
was not observed $[6,12,14]$ and assays of CYP21A2 activity from another report also showed similar to WT activities[15]. The R316Wvariations was found in normal population and shows similar to WT activities[1, 12]. We had reported the P399_E401deletion in two Turkish families that were no related to each other[13]and this mutation $15-32 \%$ of the WT activity with different assays of steroidogenic cytochrome P450s[13]. The variant G413S was found by BioventuresInc. [87],and shows similar to WT activities in several tests (Table 4)[12]. A DSD patient of Pakistani origin (17 and 21-hydroxylase deficiencies) was found to have POR mutation R498P but enzymatic characterization has not been done[29].

So far there does not seem to be any link between altered steroid profile and the common POR variant A503V[88]. The POR mutation G539R caused 90\% loss of 17,20 lyase activity and 54\% loss of the 17 $\alpha$-hydroxylase activity in CYP17A1 assays[12].The mutation C569Y is predicted to affect NADPH binding in human POR and caused87\% loss of 17,20 lyase activity and $72 \%$ loss of $17 \alpha$-hydroxylase activity[12]. The POR variant R600W has retained $7-60 \%$ of the WT activity in assays with different redox partners[33]. The C569Y mutation was found in a compound heterozygote state with another POR mutation,V608F [6]. The V608F mutation had $80 \%$ of the $17 \alpha$-hydroxylase activity and $57 \%$ of the 17,20 lyase activity in CYP17A1assays (Table 3)[12, 14]. Both C569Y and V608F caused a greater reduction in the activity ofCYP19A1 compared to their effects on activities of CYP17A1 [6, 12, 14]. Themutation H628P showed similar impact activities of both the CYP17A1 and CYP21A2 [15]. The mutation Y607C has appeared in several sequencing studies of normal populations and causes severe reduction in activities of CYP17A1 and CYP19A1 but CYP21A2 activity was similar to WT[31]. Any severe malformations were absent in a patient in whom the Y607C variant was found[12, 31]. The POR variant V631Ihad 40-50\% of the WT activity in assays with CYP17A1. A single amino acid deletion of F646 did not impact17 $\alpha$-hydroxylase activity but the 17,20 lyase activity of CYP17A1 was reduced by half[12]. Two other mutants in the NADPH binding region 
of POR, the Y578C and the E580Q have not been checked for impact on the activities of any cytochrome P450 enzymes[1].

\subsection{POR and drug metabolism}

When the POR mutations were found in patients with disordered steroid metabolism and then several variations in POR gene were identified in normal healthy individuals, we proposed that variations in POR may cause alterations in the activities of drug metabolizing cytochrome P450sbecause the POR is required for nearly all cytochrome P450s located in the endoplasmic reticulum[6, 8, 12, 89]. Several groups have now examined the effect of POR variations on activities of drug metabolizing enzymes[26, 27, 32, 90-97]as well as other POR dependent reactions[25-27, 94, 96, 98, 99].

Cytochrome P450 3A4 (CYP3A4) is the major hepatic enzyme that metabolizes a large percentage of drugs and endogenous substrates[4, 100, 101]. We found that mutations in POR can affect the enzymatic activities of CYP3A4 [26]. The POR mutant A287P (common in “Europeans”) leads to a 75\% reduction ofthe CYP3A4 enzymatic activity (Table 3)[26, 27]. The population variants R316W and G413S showedsimilar activities as the WT POR[27]. The POR mutations that affect binding of co-factor FAD (R457H, Y459H and V492E) showed noactivity in CYP3A4 assays[27]. Another two polymorphismsin POR the A503V and G504R also had similar as WT activities (Table 4)[27]. The two mutations in POR located in the NADPH binding site, the C569Y and V608F caused 65-85\% loss of the CYP3A4 activity and a cterminus truncation mutation in POR, R616X,showed no activity (Table 3)[27]. Among the mutations in FMN binding domain, the POR T142A had 75-80\% activity, the Q153R showed similar to WT activity and the POR mutant Y181D which results in loss of FMN, had no activity with CYP3A4, [27].Oursecond report on effects of POR variants with CYP3A4 indicated that variations in POR may cause changes inCYP3A4activities in patients[26, 27]. Effect of POR 
variants on CYP3A4 activities may also depend on specific substrates; the POR variant Q153R has shown 76-94\% of the WT CYP3A4 activity with substrates midazolam and erythromycin, but when testosterone and quinidine were used as substrates it had $129-150 \%$ of the WT POR activity[94]. The A503Vvariant of POR caused 20-40\% loss of CYP3A4 activity whenmidazolam and testosterone were used as substrates but when erythromycin and quinidine were used as substrates, the A503V showed similar to WT activities[94]. The POR variant G413S has been found to have similar to WT activities in two reports[27, 102].A combined analysis of several studies shows that many polymorphisms in POR(P228L, R316W, G413S, A503V and G504R)retain $>40 \%$ activity in assays with most redox partners (Table 4). In the testing of CYP2C19 and CYP1A2 activities, POR mutations A287P and R457H have been reported to cause total loss of activity[91](Table 3). The POR variant Q153R caused an increase in the activity of CYP1A2 by $144 \%$ and CYP2C19 activity by $284 \%$, similar to our observation of increased activity of aromatase with POR Q153R [103]. The POR variant A503V showed $85 \%$ of the WT activity in CYP1A2 assays and 113\% of the WT activity in assays with CYP2C19 (Table 4).

The CYP2D6 is also a major enzyme involved in drug metabolism and after CYP3A4 it is responsible for the metabolism of a large number of drugs[4]. In the assay of CYP2D6 activities with dextromethorphan and bufuralol as substrates, the A287P mutant of POR lost $75 \%$ of the activity compared to WT POR. Compared to the WT POR, the POR variant A503V showed activities of $62 \%$ with dextromethorphan as substrate and $53 \%$ when bufuralol was the substrate in CYP2D6 assays[98]. The effects of different CYP isoforms on impact of POR activities has not been studied in detail. One study[104]tested different alleles of CYP2C9 (CYP2C9.1, CYP2C9.2 and CYP2C9.3) with few POR variants and patterns were similar for all isoforms of CYP2C9[104]. 


\subsection{Population genetic differences in POR}

We analyzed all known variants in POR based on sequence and structure conservation and phylogenetic analysis to see if there are any destabilizing variations associated with particular population groups. We first compiled a list of all known variants and then checked which ones have a high score in ConSurf analysis. This list was further analyzed by structural predictions based on potential energy calculation. Several variants found in normal populations came out positive for structure stability and disease causing properties (Figure 4). Based on this we can conclude that there are people with slightly or moderately defective POR who were not diagnosed with PORD but nonetheless, may show symptoms based on environmental variations in xenobiotic exposure. Of particular concern is the difference in activities of drug metabolizing enzymes that may be severely impaired in some of these cases.

Many POR variants identified in sequencing of normal population had $>40 \%$ of the WT activities in many enzymaticassays. A sequencing study of POR from human livers added more amino acid variations (K49N, L420M and L577P)[92]. The L577P variant of POR showed loss of activities several P450 assaysutilizing drug metabolizing enzymes[92]. A study by Ulli Zanger on analysis of POR variation human liver reported 43 variations that contained 19 SNPs in protein coding regions[32]. Two combinatorial alleles, (P228L + A503V and A503V + V631I) were also identified and A503V was the common minor allele, similar to other reports [32].

Several new studies have analyzed the sequence of POR gene in specific populations. A Japanese study[30] found fourpreviously undescribedvariants (T29M, R550W, R570C and A659T). In this study theA503V was found at a higher frequency of 0.434 . Another recent study looked atvariations in POR genetically different Jewish populations and identified 6 more variants,the S102P, V164M, V191M, D344N, E398A and D648N [28]. After analysis of a large 
amount of sequencing data from 1000 Genome Project and other large sequencing studies we found the A503Vvariant of POR in different population hasa minor allele frequency from 0.12 to 0.48 (Table 5). There are some distinct trendsthat cab be identified in different populations (Figure 5). In the Caucasian and Hispanic populations, the A503Vallele frequency is 31\%, in Pacific Islanders 48\% and in Asian populations the A503Vallele is present at34-39\%. AmongJapanese population the A503V is foundin 40\% alleles andin African Americans groupsthe POR A503V is found in fewer than $16 \%$ of alleles.

Finally, we looked at some of the predicted disease causing variants in more detail by structural analysis and found several residues that show variations in normal population and have characteristics of a defective POR (Figure 6). Many such variants are found in rare cases and even with 5000 alleles analyzed, the numbers are not indicative of linkages to particular populations. However, some patterns have emerged from this analysis that are worth pursuing in functional studies in the lab. The variant T93I seems to be exclusive to South Asians, while A172T wasprevalent in European populations. The variant P284T which shows almost complete loss of activity in functional assays was found exclusively in Africans. The variant T372M linked to mixed Americans and G537R was a variant exclusive to Europeans. The Y607C seems to be most prevalent in South Asians and has shown loss of activity in some assay. In our laboratory testing we found it to severely impact aromatase activity. This was in agreement with its computational analysis that shows impact on NADPH binding. Previously we found that the mutations located in the NADPH binding site of the POR are more sensitive towards aromatase and availability of co-factors may influence their impact.

\section{Conclusions}

PORD is a complex disorder. Identifying a common link that is responsible for defects in both 17- and 21-hydroxylase activitieshas established the genetic basis of a previously 
uncharacterized disorder of steroid biosynthesis. Changes in the steroid metabolism caused by PORD aremore complex than those observed with defectsin individual proteins [105, 106], and PORD can produces many biological changes such as effects on bone formation or xenobiotic metabolism[26, 27, 107]. Many variants in POR affect the protein-protein interactions with the different redox partners, therefore, a prediction of the effects of POR variations based on information gained from single studies is difficult. PORD can be diagnosed from biochemical and hormonal analysis, and measurement of urine steroids by GC/MS is currently the best method. However, final confirmation of PORD must be done by genetic analysis. Treatment options in PORD aresupplementation of sex steroids andglucocorticoidsbased on steroid profile of the patient. Reportsof mortality in POR patients are due to skeletal malformations that lead to respiratory problems. The malformations in skeleton caused by defects in POR need orthopedic management. In diseases like malaria where deposition of polymeric heme (hemozoin) causes reduction in the levels of hepatic cytochrome P450 proteins and activities, POR variants causingreduced activities wouldaffect the severity of the disease [108, 109]. Preliminary computational docking and functional analysis suggests that the loss of activity caused by some POR variants may be reversed by introduction of external flavin[26]. However, effect of flavin treatment inPORDneeds to be tested. Another potential therapeutic option in cases of arginine to cysteine mutations is the treatment with cysteamine [110], which converts cysteine to lysine like group and may be able to neutralize some of the drastic changes caused by arginine to cysteine mutations, which occur frequently.

\section{ACKNOWLEDGMENTS}

This work has been supported by a grantfrom the Swiss National Science Foundation (31003A134926) to AVP. Some content from earlier publications[1, 2]from us was reproduced with permission from Elsevier. 


\section{References}

[1] A.V. Pandey, C.E. Flück, NADPH P450 oxidoreductase: structure, function, and pathology of diseases, Pharmacol Ther, 138 (2013) 229-254.

[2] C.E. Flück, A.V. Pandey, Chapter 3H - P450 Oxidoreductase Deficiency (PORD) in: M.I. New, O. Lekarev, A. Parsa, T.T. Yuen, B.W. O'Malley, G.D. Hammer (Eds.) Genetic Steroid Disorders, Academic Press, San Diego, 2013, pp. 125-143.

[3] D.S. Riddick, X. Ding, C.R. Wolf, T.D. Porter, A.V. Pandey, Q.Y. Zhang, J. Gu, R.D. Finn, S. Ronseaux, L.A. McLaughlin, C.J. Henderson, L. Zou, C.E. Flück, NADPH-cytochrome P450 oxidoreductase: roles in physiology, pharmacology, and toxicology, Drug Metab Dispos, 41 (2013) 12-23.

[4] U.M. Zanger, M. Schwab, Cytochrome P450 enzymes in drug metabolism: regulation of gene expression, enzyme activities, and impact of genetic variation, Pharmacol Ther, 138 (2013) 103-141. [5] A.V. Pandey, P. Sproll, Pharmacogenomics of human P450 oxidoreductase, Front Pharmacol, 5 (2014) 103.

[6] C.E. Flück, T. Tajima, A.V. Pandey, W. Arlt, K. Okuhara, C.F. Verge, E.W. Jabs, B.B. Mendonca, K. Fujieda, W.L. Miller, Mutant P450 oxidoreductase causes disordered steroidogenesis with and without Antley-Bixler syndrome, Nat Genet, 36 (2004) 228-230.

[7] W.L. Miller, N. Huang, C.E. Flück, A.V. Pandey, P450 oxidoreductase deficiency, Lancet, 364 (2004) 1663.

[8] A.V. Pandey, C.E. Flück, N. Huang, T. Tajima, K. Fujieda, W.L. Miller, P450 oxidoreductase deficiency: A new disorder of steroidogenesis affecting all microsomal P450 enzymes., Endocrine Research, 30 (2004) 881-888.

[9] R.E. Peterson, J. Imperato-McGinley, T. Gautier, C.H.L. Shackleton, Male pseudohermaphroditism due to multiple defects in steroid-biosynthetic microsomal mixed-function oxidases. A new variant of congenital adrenal hyperplasia, N Engl J Med, 313 (1985) 1182-1191.

[10] W.L. Miller, Congenital adrenal hyperplasia, N Engl J Med, 314 (1986) 1321-1322.

[11] R.I. Kelley, L.E. Kratz, R.L. Glaser, M.L. Netzloff, L.M. Wolf, E.W. Jabs, Abnormal sterol metabolism in a patient with Antley-Bixler syndrome and ambiguous genitalia, Am J Med Genet, 110 (2002) 95-102.

[12] N. Huang, A.V. Pandey, V. Agrawal, W. Reardon, P.D. Lapunzina, D. Mowat, E.W. Jabs, G. Van Vliet, J. Sack, C.E. Flück, W.L. Miller, Diversity and function of mutations in p450 oxidoreductase in patients with Antley-Bixler syndrome and disordered steroidogenesis, Am J Hum Genet, 76 (2005) 729-749. [13] C.E. Flück, D. Mallet, G. Hofer, D. Samara-Boustani, J. Leger, M. Polak, Y. Morel, A.V. Pandey, Deletion of P399_E401 in NADPH cytochrome P450 oxidoreductase results in partial mixed oxidase deficiency, Biochem Biophys Res Commun, 412 (2011) 572-577.

[14] A.V. Pandey, P. Kempna, G. Hofer, P.E. Mullis, C.E. Flück, Modulation of human CYP19A1 activity by mutant NADPH P450 oxidoreductase, Mol Endocrinol, 21 (2007) 2579-2595.

[15] V. Dhir, H.E. Ivison, N. Krone, C.H. Shackleton, A.J. Doherty, P.M. Stewart, W. Arlt, Differential inhibition of CYP17A1 and CYP21A2 activities by the P450 oxidoreductase mutant A287P, Mol Endocrinol, 21 (2007) 1958-1968.

[16] C.E. Flück, A.V. Pandey, Steroidogenesis of the testis - new genes and pathways., Annales d'Endocrinologie, (2014).

[17] W.L. Miller, R.J. Auchus, The molecular biology, biochemistry, and physiology of human steroidogenesis and its disorders, Endocr Rev, 32 (2011) 81-151.

[18] N. Bouchoucha, D. Samara-Boustani, A.V. Pandey, H. Bony-Trifunovic, G. Hofer, Y. Aigrain, M. Polak, C.E. Flück, Characterization of a novel CYP19A1 (aromatase) R192H mutation causing virilization of a $46, X X$ newborn, undervirilization of the $46, X Y$ brother, but no virilization of the mother during pregnancies, Mol Cell Endocrinol, (2014).

[19] M. Fukami, K. Homma, T. Hasegawa, T. Ogata, Backdoor pathway for dihydrotestosterone biosynthesis: Implications for normal and abnormal human sex development, Dev Dyn, (2012).

[20] C.E. Flück, A.V. Pandey, Clinical and biochemical consequences of p450 oxidoreductase deficiency, Endocr Dev, 20 (2011) 63-79. 
[21] C.E. Flück, M. Meyer-Böni, A.V. Pandey, P. Kempna, W.L. Miller, E.J. Schoenle, A. Biason-Lauber, Why boys will be boys: Two pathways of fetal testicular androgen biosynthesis are needed for male sexual differentiation., Am J Hum Genet, 89 (2011) 201-218.

[22] A. Biason-Lauber, W.L. Miller, A.V. Pandey, C.E. Flück, Of marsupials and men: "Backdoor" dihydrotestosterone synthesis in male sexual differentiation, Mol Cell Endocrinol, 371 (2013) 124-132. [23] A. Biason-Lauber, A.V. Pandey, W.L. Miller, C.E. Flück, Chapter 4B - Marsupial Pathway in Humans, in: M.I. New, O. Lekarev, A. Parsa, T.T. Yuen, B.W. O'Malley, G.D. Hammer (Eds.) Genetic Steroid Disorders, Academic Press, San Diego, 2014, pp. 215-224.

[24] S.C. Sim, W.L. Miller, X.B. Zhong, W. Arlt, T. Ogata, X. Ding, C.R. Wolf, C.E. Flück, A.V. Pandey, C.J. Henderson, T.D. Porter, A.K. Daly, D.W. Nebert, M. Ingelman-Sundberg, Nomenclature for alleles of the cytochrome P450 oxidoreductase gene, Pharmacogenet Genomics, 19 (2009) 565-566.

[25] A.V. Pandey, C.E. Flück, P.E. Mullis, Altered heme catabolism by heme oxygenase-1 caused by mutations in human NADPH cytochrome P450 reductase, Biochem Biophys Res Commun, 400 (2010) 374-378.

[26] C. Nicolo, C.E. Flück, P.E. Mullis, A.V. Pandey, Restoration of mutant cytochrome P450 reductase activity by external flavin, Mol Cell Endocrinol, 321 (2010) 245-252.

[27] C.E. Flück, P.E. Mullis, A.V. Pandey, Reduction in hepatic drug metabolizing CYP3A4 activities caused by P450 oxidoreductase mutations identified in patients with disordered steroid metabolism, Biochem Biophys Res Commun, 401 (2010) 149-153.

[28] M. Tomkova, C.C. Marohnic, D. Gurwitz, O. Seda, B.S. Masters, P. Martasek, Identification of six novel P450 oxidoreductase missense variants in Ashkenazi and Moroccan Jewish populations, Pharmacogenomics, 13 (2012) 543-554.

[29] N. Krone, N. Reisch, J. Idkowiak, V. Dhir, H.E. Ivison, B.A. Hughes, I.T. Rose, D.M. O'Neil, R. Vijzelaar, M.J. Smith, F. MacDonald, T.R. Cole, N. Adolphs, J.S. Barton, E.M. Blair, S.R. Braddock, F. Collins, D.L. Cragun, M.T. Dattani, R. Day, S. Dougan, M. Feist, M.E. Gottschalk, J.W. Gregory, M. Haim, R. Harrison, A.H. Olney, B.P. Hauffa, P.C. Hindmarsh, R.J. Hopkin, P.E. Jira, M. Kempers, M.N. Kerstens, M.M. Khalifa, B. Kohler, D. Maiter, S. Nielsen, S.M. O'Riordan, C.L. Roth, K.P. Shane, M. Silink, N.M. Stikkelbroeck, E. Sweeney, M. Szarras-Czapnik, J.R. Waterson, L. Williamson, M.F. Hartmann, N.F. Taylor, S.A. Wudy, E.M. Malunowicz, C.H. Shackleton, W. Arlt, Genotype-phenotype analysis in congenital adrenal hyperplasia due to P450 oxidoreductase deficiency, J Clin Endocrinol Metab, 97 (2012) E257-267.

[30] Y. Saito, N. Yamamoto, N. Katori, K. Maekawa, H. Fukushima-Uesaka, D. Sugimoto, K. Kurose, K. Sai, N. Kaniwa, J. Sawada, H. Kunitoh, Y. Ohe, T. Yoshida, Y. Matsumura, N. Saijo, H. Okuda, T. Tamura, Genetic polymorphisms and haplotypes of por, encoding cytochrome p450 oxidoreductase, in a Japanese population, Drug Metab Pharmacokinet, 26 (2011) 107-116.

[31] J. Idkowiak, E.M. Malunowicz, V. Dhir, N. Reisch, M. Szarras-Czapnik, D.M. Holmes, C.H. Shackleton, J.D. Davies, I.A. Hughes, N. Krone, W. Arlt, Concomitant mutations in the P450 oxidoreductase and androgen receptor genes presenting with $46, \mathrm{XY}$ disordered sex development and androgenization at adrenarche, J Clin Endocrinol Metab, 95 (2010) 3418-3427.

[32] A.M. Gomes, S. Winter, K. Klein, M. Turpeinen, E. Schaeffeler, M. Schwab, U.M. Zanger, Pharmacogenomics of human liver cytochrome P450 oxidoreductase: multifactorial analysis and impact on microsomal drug oxidation, Pharmacogenomics, 10 (2009) 579-599.

[33] N. Huang, V. Agrawal, K.M. Giacomini, W.L. Miller, Genetics of P450 oxidoreductase: sequence variation in 842 individuals of four ethnicities and activities of 15 missense mutations, Proc Natl Acad Sci U S A, 105 (2008) 1733-1738.

[34] J.M. Ko, C.K. Cheon, G.H. Kim, H.W. Yoo, A case of Antley-Bixler syndrome caused by compound heterozygous mutations of the cytochrome P450 oxidoreductase gene, Eur J Pediatr, 168 (2009) 877 880.

[35] W.M. But, I.F. Lo, C.C. Shek, W.Y. Tse, S.T. Lam, Ambiguous genitalia, impaired steroidogenesis, and Antley-Bixler syndrome in a patient with P450 oxidoreductase deficiency, Hong Kong Med J, 16 (2010) 59-62.

[36] M. Puiu, C. Pienar, A.C. Emandi, S. Arghirescu, C. Popa, I. Micle, A Case of Antley Bixler Syndrome: Diagnosis and Outcome, Acta Endocrinol-Buch, 8 (2012) 479-484. 
[37] J.C. Herkert, E.E. Blaauwwiekel, A. Hoek, H.E. Veenstra-Knol, I.P. Kema, W. Arlt, M.N. Kerstens, A rare cause of congenital adrenal hyperplasia: Antley-Bixler syndrome due to POR deficiency, Netherlands Journal of Medicine, 69 (2011) 281-283.

[38] E. Krieger, T. Darden, S.B. Nabuurs, A. Finkelstein, G. Vriend, Making optimal use of empirical energy functions: force-field parameterization in crystal space, Proteins, 57 (2004) 678-683.

[39] G. Vriend, WHAT IF: a molecular modeling and drug design program, J Mol Graph, 8 (1990) 52-56, 29.

[40] R.W. Hooft, G. Vriend, C. Sander, E.E. Abola, Errors in protein structures, Nature, 381 (1996) 272. [41] J.U. Bowie, R. Luthy, D. Eisenberg, A method to identify protein sequences that fold into a known three-dimensional structure, Science, 253 (1991) 164-170.

[42] R. Luthy, J.U. Bowie, D. Eisenberg, Assessment of protein models with three-dimensional profiles, Nature, 356 (1992) 83-85.

[43] G.N. Ramachandran, C. Ramakrishnan, V. Sasisekharan, Stereochemistry of polypeptide chain configurations, J Mol Biol, 7 (1963) 95-99.

[44] R.W. Hooft, C. Sander, G. Vriend, Objectively judging the quality of a protein structure from a Ramachandran plot, Comput Appl Biosci, 13 (1997) 425-430.

[45] P.A. Hubbard, A.L. Shen, R. Paschke, C.B. Kasper, J.J. Kim, NADPH-cytochrome P450 oxidoreductase. Structural basis for hydride and electron transfer, J Biol Chem, 276 (2001) 29163-29170.

[46] M. Wang, D.L. Roberts, R. Paschke, T.M. Shea, B.S. Masters, J.J. Kim, Three-dimensional structure of NADPH-cytochrome P450 reductase: prototype for FMN- and FAD-containing enzymes, Proc Natl Acad Sci U S A, 94 (1997) 8411-8416.

[47] D. Hamdane, C. Xia, S.C. Im, H. Zhang, J.J. Kim, L. Waskell, Structure and function of an NADPHcytochrome P450 oxidoreductase in an open conformation capable of reducing cytochrome P450, J Biol Chem, (2009).

[48] H. Liu, M. Elstner, E. Kaxiras, T. Frauenheim, J. Hermans, W. Yang, Quantum mechanics simulation of protein dynamics on long timescale, Proteins, 44 (2001) 484-489.

[49] C.L. Worth, G.R. Bickerton, A. Schreyer, J.R. Forman, T.M. Cheng, S. Lee, S. Gong, D.F. Burke, T.L. Blundell, A structural bioinformatics approach to the analysis of nonsynonymous single nucleotide polymorphisms (nsSNPs) and their relation to disease, J Bioinform Comput Biol, 5 (2007) 1297-1318. [50] C.M. Topham, N. Srinivasan, T.L. Blundell, Prediction of the stability of protein mutants based on structural environment-dependent amino acid substitution and propensity tables, Protein Eng, 10 (1997) 7-21.

[51] R.E. Smith, S.C. Lovell, D.F. Burke, R.W. Montalvao, T.L. Blundell, Andante: reducing side-chain rotamer search space during comparative modeling using environment-specific substitution probabilities, Bioinformatics, 23 (2007) 1099-1105.

[52] H. Ashkenazy, E. Erez, E. Martz, T. Pupko, N. Ben-Tal, ConSurf 2010: calculating evolutionary conservation in sequence and structure of proteins and nucleic acids, Nucleic Acids Res, 38 (2010) W529-533.

[53] F. Glaser, T. Pupko, I. Paz, R.E. Bell, D. Bechor-Shental, E. Martz, N. Ben-Tal, ConSurf: identification of functional regions in proteins by surface-mapping of phylogenetic information, Bioinformatics, 19 (2003) 163-164.

[54] A. Auton, L.D. Brooks, R.M. Durbin, E.P. Garrison, H.M. Kang, J.O. Korbel, J.L. Marchini, S. McCarthy, G.A. McVean, G.R. Abecasis, A global reference for human genetic variation, Nature, 526 (2015) 68-74. [55] M. Hirakawa, T. Tanaka, Y. Hashimoto, M. Kuroda, T. Takagi, Y. Nakamura, JSNP: a database of common gene variations in the Japanese population, Nucleic Acids Res, 30 (2002) 158-162.

[56] W. Arlt, E.A. Walker, N. Draper, H.E. Ivison, J.P. Ride, F. Hammer, S.M. Chalder, M. BoruckaMankiewicz, B.P. Hauffa, E.M. Malunowicz, P.M. Stewart, C.H. Shackleton, Congenital adrenal hyperplasia caused by mutant $\mathrm{P} 450$ oxidoreductase and human androgen synthesis: analytical study, Lancet, 363 (2004) 2128-2135.

[57] M. Adachi, K. Tachibana, Y. Asakura, T. Yamamoto, K. Hanaki, A. Oka, Compound heterozygous mutations of cytochrome P450 oxidoreductase gene (POR) in two patients with Antley-Bixler syndrome, Am J Med Genet, 128A (2004) 333-339. 
[58] M. Fukami, T. Hasegawa, R. Horikawa, T. Ohashi, G. Nishimura, K. Homma, T. Ogata, Cytochrome P450 oxidoreductase deficiency in three patients initially regarded as having 21-hydroxylase deficiency and/or aromatase deficiency: diagnostic value of urine steroid hormone analysis, Pediatr Res, 59 (2006) 276-280.

[59] M. Fukami, R. Horikawa, T. Nagai, T. Tanaka, Y. Naiki, N. Sato, T. Okuyama, H. Nakai, S. Soneda, K. Tachibana, N. Matsuo, S. Sato, K. Homma, G. Nishimura, T. Hasegawa, T. Ogata, Cytochrome P450 oxidoreductase gene mutations and Antley-Bixler syndrome with abnormal genitalia and/or impaired steroidogenesis: molecular and clinical studies in 10 patients, J Clin Endocrinol Metab, 90 (2005) 414426.

[60] M. Fukami, G. Nishimura, K. Homma, T. Nagai, K. Hanaki, A. Uematsu, T. Ishii, C. Numakura, H. Sawada, M. Nakacho, T. Kowase, K. Motomura, H. Haruna, M. Nakamura, A. Ohishi, M. Adachi, T. Tajima, Y. Hasegawa, T. Hasegawa, R. Horikawa, K. Fujieda, T. Ogata, Cytochrome P450 oxidoreductase deficiency: identification and characterization of biallelic mutations and genotype-phenotype correlations in 35 Japanese patients, J Clin Endocrinol Metab, 94 (2009) 1723-1731.

[61] K. Homma, T. Hasegawa, T. Nagai, M. Adachi, R. Horikawa, I. Fujiwara, T. Tajima, R. Takeda, M.

Fukami, T. Ogata, Urine steroid hormone profile analysis in cytochrome P450 oxidoreductase deficiency: implication for the backdoor pathway to dihydrotestosterone, J Clin Endocrinol Metab, 91 (2006) 26432649.

[62] J. Idkowiak, S. O'Riordan, N. Reisch, E.M. Malunowicz, F. Collins, M.N. Kerstens, B. Kohler, L.M. Graul-Neumann, M. Szarras-Czapnik, M. Dattani, M. Silink, C.H. Shackleton, D. Maiter, N. Krone, W. Arlt, Pubertal presentation in seven patients with congenital adrenal hyperplasia due to P450 oxidoreductase deficiency, J Clin Endocrinol Metab, 96 (2011) E453-462.

[63] T. Sahakitrungruang, N. Huang, M.K. Tee, V. Agrawal, W.E. Russell, P. Crock, N. Murphy, C.J. Migeon, W.L. Miller, Clinical, genetic, and enzymatic characterization of P450 oxidoreductase deficiency in four patients, J Clin Endocrinol Metab, 94 (2009) 4992-5000.

[64] R.R. Scott, L.G. Gomes, N. Huang, G. Van Vliet, W.L. Miller, Apparent manifesting heterozygosity in P450 oxidoreductase deficiency and its effect on coexisting 21-hydroxylase deficiency, J Clin Endocrinol Metab, 92 (2007) 2318-2322.

[65] W. Reardon, A. Smith, J.W. Honour, P. Hindmarsh, D. Das, G. Rumsby, I. Nelson, S. Malcolm, L. Ades, D. Sillence, D. Kumar, C. DeLozier-Blanchet, S. McKee, T. Kelly, W.L. McKeehan, M. Baraitser, R.M. Winter, Evidence for digenic inheritance in some cases of Antley-Bixler syndrome?, J Med Genet, 37 (2000) 26-32.

[66] C.H.L. Shackleton, Role of a disordered steroid metabolome in the elucidation of sterol and steroid biosynthesis., Lipids, 47 (2012) 1-12.

[67] Y. Koyama, K. Homma, M. Fukami, M. Miwa, K. Ikeda, T. Ogata, T. Hasegawa, M. Murata, Two-step biochemical differential diagnosis of classic 21-hydroxylase deficiency and cytochrome P450

oxidoreductase deficiency in Japanese infants by GC-MS measurement of urinary pregnanetriolone/ tetrahydroxycortisone ratio and 11beta-hydroxyandrosterone, Clin Chem, 58 (2012) 741-747.

[68] N. Krone, B.A. Hughes, G.G. Lavery, P.M. Stewart, W. Arlt, C.H. Shackleton, Gas chromatography/mass spectrometry (GC/MS) remains a pre-eminent discovery tool in clinical steroid investigations even in the era of fast liquid chromatography tandem mass spectrometry (LC/MS/MS), J Steroid Biochem Mol Biol, 121 (2010) 496-504.

[69] C. Shackleton, J. Marcos, W. Arlt, B.P. Hauffa, Prenatal diagnosis of P450 oxidoreductase deficiency (ORD): a disorder causing low pregnancy estriol, maternal and fetal virilization, and the Antley-Bixler syndrome phenotype, Am J Med Genet, 129A (2004) 105-112.

[70] R.J. Auchus, The backdoor pathway to dihydrotestosterone. Trends Endocrinol Metab, 15 (2004) 432-438.

[71] C.E. Flück, A.V. Pandey, P450 oxidoreductase deficiency (PORD). in: M.I. New, O. Lekarev, A. Parsa, T. Yuen, B. O'Mally, G. Hammer (Eds.) Genetic Steroid Disorders, Academic Press, New York, 2013, pp. 122-143.

[72] R. Antley, D. Bixler, Trapezoidocephaly, midfacial hypoplasia and cartilage abnormalities with multiple synostoses and skeletal fractures, Birth Defects Orig Artic Ser, 11 (1975) 397-401. 
[73] C.D. DeLozier, R.M. Antley, R. Williams, N. Green, R.M. Heller, D. Bixler, E. Engel, The syndrome of multisynostotic osteodysgenesis with long-bone fractures, Am J Med Genet, 7 (1980) 391-403.

[74] S. Hassell, M.G. Butler, Antley-Bixler syndrome: report of a patient and review of literature, Clin Genet, 46 (1994) 372-376.

[75] G. Crisponi, C. Porcu, M.E. Piu, Antley-Bixler syndrome: case report and review of the literature, Clin Dysmorphol, 6 (1997) 61-68.

[76] T. Ono, K. Bloch, Solubilization and partial characterization of rat liver squalene epoxidase, J Biol Chem, 250 (1975) 1571-1579.

[77] N. Debeljak, M. Fink, D. Rozman, Many facets of mammalian lanosterol 14a-demethylase from the evolutionarily conserved cytochrome P450 family CYP51., Arch Biochem Biophys, 409 (2003) 159-171.

[78] F. Gofflot, C. Hars, F. Illien, F. Chevy, C. Wolf, J.J. Picard, C. Roux, Molecular mechanisms underlying limb anomalies associated with cholesterol deficiency during gestation: implications of Hedgehog signaling, Hum Mol Genet, 12 (2003) 1187-1198.

[79] A. Aguilar, S. Wu, F. De Luca, P450 oxidoreductase expressed in rat chondrocytes modulates chondrogenesis via cholesterol- and Indian Hedgehog-dependent mechanisms, Endocrinology, 150 (2009) 2732-2739.

[80] V. Ribes, D.M. Otto, L. Dickmann, K. Schmidt, B. Schuhbaur, C. Henderson, R. Blomhoff, C.R. Wolf, C. Tickle, P. Dolle, Rescue of cytochrome P450 oxidoreductase (Por) mouse mutants reveals functions in vasculogenesis, brain and limb patterning linked to retinoic acid homeostasis, Dev Biol, 303 (2007) 6681.

[81] G.S. Lee, D.M. Kochhar, M.D. Collins, Retinoid-induced limb malformations, Curr Pharm Des, 10 (2004) 2657-2699.

[82] D.M. Otto, C.J. Henderson, D. Carrie, M. Davey, T.E. Gundersen, R. Blomhoff, R.H. Adams, C. Tickle, C.R. Wolf, Identification of novel roles of the cytochrome P450 system in early embryogenesis: effects on vasculogenesis and retinoic acid homeostasis, Mol Cell Biol, 23 (2003) 6103-6116.

[83] K. Schmidt, C. Hughes, J.A. Chudek, S.R. Goodyear, R.M. Aspden, R. Talbot, T.E. Gundersen, R. Blomhoff, C. Henderson, C.R. Wolf, C. Tickle, Cholesterol metabolism: the main pathway acting downstream of cytochrome P450 oxidoreductase in skeletal development of the limb, Mol Cell Biol, 29 (2009) 2716-2729.

[84] M. Fukami, T. Nagai, H. Mochizuki, K. Muroya, G. Yamada, K. Takitani, T. Ogata, Anorectal and urinary anomalies and aberrant retinoic acid metabolism in cytochrome P450 oxidoreductase deficiency, Mol Genet Metab, 100 (2010) 269-273.

[85] K. Laue, H.M. Pogoda, P.B. Daniel, A. van Haeringen, Y. Alanay, S. von Ameln, M. Rachwalski, T. Morgan, M.J. Gray, M.H. Breuning, G.M. Sawyer, A.J. Sutherland-Smith, P.G. Nikkels, C. Kubisch, W. Bloch, B. Wollnik, M. Hammerschmidt, S.P. Robertson, Craniosynostosis and multiple skeletal anomalies in humans and zebrafish result from a defect in the localized degradation of retinoic acid, Am J Hum Genet, 89 (2011) 595-606.

[86] C. Xia, S.P. Panda, C.C. Marohnic, P. Martasek, B.S. Masters, J.J. Kim, Structural basis for human NADPH-cytochrome P450 oxidoreductase deficiency, Proc Natl Acad Sci U S A, 108 (2011) 13486-13491. [87] J.F. Solus, B.J. Arietta, J.R. Harris, D.P. Sexton, J.Q. Steward, C. McMunn, P. Ihrie, J.M. Mehall, T.L. Edwards, E.P. Dawson, Genetic variation in eleven phase I drug metabolism genes in an ethnically diverse population, Pharmacogenomics, 5 (2004) 895-931.

[88] P. Utriainen, S. Laakso, J. Jaaskelainen, R. Voutilainen, Polymorphisms of POR, SULT2A1 and HSD11B1 in children with premature adrenarche, Metabolism, 61 (2012) 1215-1219.

[89] C.E. Fluck, C. Nicolo, A.V. Pandey, Clinical, structural and functional implications of mutations and polymorphisms in human NADPH P450 oxidoreductase, Fundam Clin Pharmacol, 21 (2007) 399-410. [90] M. Kranendonk, C.C. Marohnic, S.P. Panda, M.P. Duarte, J.S. Oliveira, B.S. Masters, J. Rueff, Impairment of human CYP1A2-mediated xenobiotic metabolism by Antley-Bixler syndrome variants of cytochrome P450 oxidoreductase, Arch Biochem Biophys, 475 (2008) 93-99.

[91] V. Agrawal, N. Huang, W.L. Miller, Pharmacogenetics of P450 oxidoreductase: effect of sequence variants on activities of CYP1A2 and CYP2C19, Pharmacogenet Genomics, 18 (2008) 569-576. 
[92] S.N. Hart, S. Wang, K. Nakamoto, C. Wesselman, Y. Li, X.B. Zhong, Genetic polymorphisms in cytochrome P450 oxidoreductase influence microsomal P450-catalyzed drug metabolism, Pharmacogenet Genomics, 18 (2008) 11-24.

[93] D. Tomalik-Scharte, D. Maiter, J. Kirchheiner, H.E. Ivison, U. Fuhr, W. Arlt, Impaired hepatic drug and steroid metabolism in congenital adrenal hyperplasia due to P450 oxidoreductase deficiency, Eur J Endocrinol, 163 (2010) 919-924.

[94] V. Agrawal, J.H. Choi, K.M. Giacomini, W.L. Miller, Substrate-specific modulation of CYP3A4 activity by genetic variants of cytochrome P450 oxidoreductase, Pharmacogenet Genomics, 20 (2010) 611-618. [95] B. Oneda, S. Crettol, E. Jaquenoud Sirot, M. Bochud, N. Ansermot, C.B. Eap, The P450 oxidoreductase genotype is associated with CYP3A activity in vivo as measured by the midazolam phenotyping test, Pharmacogenet Genomics, 19 (2009) 877-883.

[96] C.C. Marohnic, S.P. Panda, K. McCammon, J. Rueff, B.S. Masters, M. Kranendonk, Human cytochrome P450 oxidoreductase deficiency caused by the Y181D mutation: molecular consequences and rescue of defect, Drug Metab Dispos, 38 (2010) 332-340.

[97] W.L. Miller, N. Huang, V. Agrawal, K.M. Giacomini, Genetic variation in human P450 oxidoreductase, Mol Cell Endocrinol, 300 (2009) 180-184.

[98] D. Sandee, K. Morrissey, V. Agrawal, H.K. Tam, M.A. Kramer, T.S. Tracy, K.M. Giacomini, W.L. Miller, Effects of genetic variants of human P450 oxidoreductase on catalysis by CYP2D6 in vitro, Pharmacogenet Genomics, 20 (2010) 677-686.

[99] X. Zhang, L. Li, X. Ding, L.S. Kaminsky, Identification of cytochrome P450 oxidoreductase gene variants that are significantly associated with the interindividual variations in warfarin maintenance dose, Drug Metab Dispos, 39 (2011) 1433-1439.

[100] U.A. Meyer, U.M. Zanger, M. Schwab, Omics and drug response, Annu Rev Pharmacol Toxicol, 53 (2013) 475-502.

[101] K. Klein, U.M. Zanger, Pharmacogenomics of Cytochrome P450 3A4: Recent Progress Toward the "Missing Heritability" Problem, Front Genet, 4 (2013) 12.

[102] D. Moutinho, C.C. Marohnic, S.P. Panda, J. Rueff, B.S. Masters, M. Kranendonk, Altered human CYP3A4 activity caused by Antley-Bixler syndrome-related variants of NADPH-cytochrome P450 oxidoreductase measured in a robust in vitro system, Drug Metab Dispos, 40 (2012) 754-760.

[103] C.E. Flück, A.V. Pandey, Impact on CYP19A1 activity by mutations in NADPH cytochrome P450 oxidoreductase, J Steroid Biochem Mol Biol, (2016).

[104] M. Subramanian, V. Agrawal, D. Sandee, H.K. Tam, W.L. Miller, T.S. Tracy, Effect of P450 oxidoreductase variants on the metabolism of model substrates mediated by CYP2C9.1, CYP2C9.2, and CYP2C9.3, Pharmacogenet Genomics, 22 (2012) 590-597.

[105] C.E. Flück, A.V. Pandey, B. Dick, N. Camats, M. Fernandez-Cancio, M. Clemente, M. Gussinye, A. Carrascosa, P.E. Mullis, L. Audi, Characterization of novel StAR (steroidogenic acute regulatory protein) mutations causing non-classic lipoid adrenal hyperplasia, PLoS One, 6 (2011) e20178.

[106] M. Janner, A.V. Pandey, P.E. Mullis, C.E. Flück, Clinical and biochemical description of a novel CYP21A2 gene mutation 962_963insA using a new 3D model for the P450c21 protein, Eur J Endocrinol, 155 (2006) 143-151.

[107] C.J. Henderson, G.J. Pass, C.R. Wolf, The hepatic cytochrome P450 reductase null mouse as a tool to identify a successful candidate entity, Toxicol Lett, 162 (2006) 111-117.

[108] A.V. Pandey, B.L. Tekwani, V.C. Pandey, Characterization of Hemozoin from Liver and Spleen of Mice Infected with Plasmodium-Yoelli, a Rodent Malaria Parasite, Biomedical Research-Tokyo, 16 (1995) 115-120.

[109] A.V. Pandey, B.L. Tekwani, V.C. Pandey, Effect of Plasmodium yoelii infection on constitutive and phenobarbitone inducible mixed function oxidase system of mice., Journal of Parasitic Diseases, 20 (1996) 141-144.

[110] C. Inauen, V. Rufenacht, A.V. Pandey, L. Hu, H. Blom, J.M. Nuoffer, J. Haberle, Effect of Cysteamine on Mutant ASL Proteins with Cysteine for Arginine Substitutions, Mol Diagn Ther, (2016).

[111] S.A. Wudy, M.F. Hartmann, N. Draper, P.M. Stewart, W. Arlt, A male twin infant with skull deformity and elevated neonatal 17-hydroxyprogesterone: a prismatic case of P450 oxidoreductase deficiency, Endocr Res, 30 (2004) 957-964. 
[112] L. Williamson, W. Arlt, C. Shackleton, R.I. Kelley, S.R. Braddock, Linking Antley-Bixler syndrome and congenital adrenal hyperplasia: a novel case of P450 oxidoreductase deficiency, Am J Med Genet A, 140A (2006) 1797-1803.

[113] E. Hershkovitz, R. Parvari, S.A. Wudy, M.F. Hartmann, L.G. Gomes, N. Loewental, W.L. Miller, Homozygous mutation G539R in the gene for P450 oxidoreductase in a family previously diagnosed as having 17,20-lyase deficiency, J Clin Endocrinol Metab, 93 (2008) 3584-3588.

[114] J.C. Herkert, E.E. Blaauwwiekel, A. Hoek, H.E. Veenstra-Knol, I.P. Kema, W. Arlt, M.N. Kerstens, A rare cause of congenital adrenal hyperplasia: Antley-Bixler syndrome due to POR deficiency, Neth J Med, 69 (2011) 281-283.

[115] G. Guaragna-Filho, C.C. Castro, R.R. Carvalho, F.B. Coeli, L.F. Ferraz, R.J. Petroli, M.P. Mello, L.E. Sewaybricker, S.H. Lemos-Marini, L.F. D'Souza-Li, M.L. Miranda, A.T. Maciel-Guerra, G. Guerra-Junior, 46,XX DSD and Antley-Bixler syndrome due to novel mutations in the cytochrome P450 oxidoreductase gene, Arq Bras Endocrinol Metabol, 56 (2012) 578-585.

[116] D. Sanchez-Garvin, S. Albaladejo, B. Ezquieta, R. Corripio, Disorder of sex development as a diagnostic clue in the first Spanish known newborn with P450 oxidoreductase deficiency, BMJ Case Rep, 2013 (2013).

[117] N. Reisch, J. Idkowiak, B.A. Hughes, H.E. Ivison, O.A. Abdul-Rahman, L.G. Hendon, A.H. Olney, S. Nielsen, R. Harrison, E.M. Blair, V. Dhir, N. Krone, C.H. Shackleton, W. Arlt, Prenatal diagnosis of congenital adrenal hyperplasia caused by P450 oxidoreductase deficiency, J Clin Endocrinol Metab, 98 (2013) E528-536.

[118] E. Oldani, C. Garel, M. Bucourt, L. Carbillon, Prenatal Diagnosis of Antley-Bixler Syndrome and POR Deficiency, Am J Case Rep, 16 (2015) 882-885.

[119] X. Chen, L.Q. Pan, H. Naranmandura, S. Zeng, S.Q. Chen, Influence of Various Polymorphic Variants of Cytochrome P450 Oxidoreductase (POR) on Drug Metabolic Activity of CYP3A4 and CYP2B6, Plos One, 7 (2012). 


\section{Legends to figures:}

Figure 1 - Several roles of P450 oxidoreductase in reactions of cytochrome P450s involved in metabolism of steroids. Supply of redox equivalents from NADPH through POR is necessary for the many unique metabolic reactions performed by P450 enzymes, especially the synthesis of steroid hormones.

Figure 2 - POR is linked to multiple pathways of steroid biosynthesis.In the first steps of steroid biosynthesis cholesterol is transported to mitochondrion by steroidogenic acute regulatory protein (StAR). Then inside the mitochondria the cholesterol is metabolized by CYP11A1 to pregnenolone and adrenodoxin and adrenodoxin reductase act as redox mediators in this reaction. The pregnenolone produced in mitochondria is further metabolized in the endoplasmic reticulum to downstream products 17OHPreg, DHEA, androstenedione or androstenediol and then this process continues to production of testosterone in the Leydig cells of the testes. Testosterone is metabolized further to dihydrotesterone (DHT) in the genital skin. The alternate pathway of steroid metabolism proceeds from 17OHPreg to 17OHProg, $17 \mathrm{OH}-$ DHP, 17OH-Allo, androsterone, androstanediol (A'diol) and then to DHT in the testis. In the placenta, DHEA is converted to androstenedione and then to testosterone, which further metabolized to estrogens. In fetal liver, inactive precursor DHEAS converted to 16aDHEAS, which get converted to 16aDHEA in placenta to produce estrogen. The estrogen biosynthesis process requires CYP19A1 activity that is mainly dependent on POR. The deficiency in POR can alter the enzymatic reactions of many cytochrome P450 enzymes and these changes can be variable based on structural properties of the mutation and nature of the redox partner.

Abbreviations:CYP11A1 (P450scc, cholesterol side-chain cleavage enzyme), StAR (steroidogenic acute regulatory protein),FDX1, Adrenodoxin; FDXR, NADPH adrenodoxin

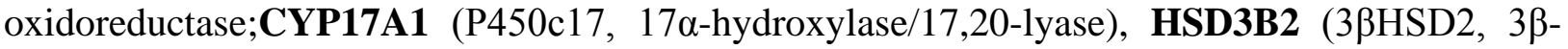
hydroxysteroid dehydrogenase, type 2), CYB5, cytochrome $b_{5} ; \quad$ POR, P450 oxidoreductase;HSD17B3 (17ßHSD3, 17 $\beta$-hydroxysteroid dehydrogenase, type 3), and SRD5A2 (5 $\alpha$-reductase, type 2). The alternative pathwayhas four additional enzymes: SRD5A1

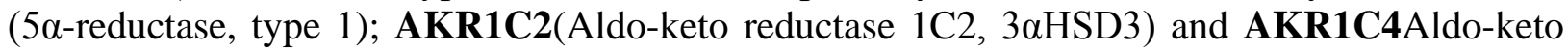

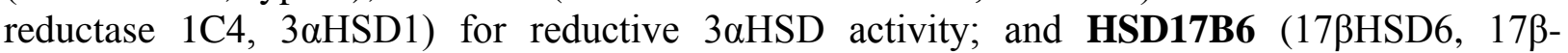
hydroxysteroid dehydrogenase, type 6) and/or AKR1C2/4 for oxidative 3aHSD activity. Full steroid names: 170HPreg, 17-hydroxypregnenolone; 17OHProg, 17-hydroxyprogesterone;

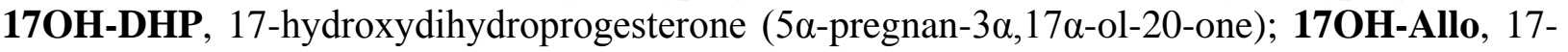

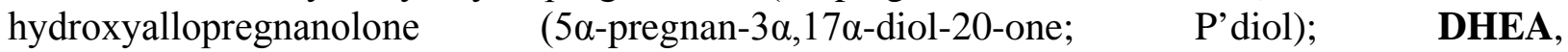
dehydroepiandrosterone.

Figure 3:Amino acid changes in POR identified in patients with PORD. A ribbons model of the x-ray crystal structure of human POR protein (PDB: 3QE2). The model is colored in rainbow colors with violet at the $\mathrm{N}$-terminus and red at the C-terminus. The co-factors FMN, FAD and NADPH are shown as sticks. Mutations found in patients with PORD are shown as ball and sticks. Mutations that caused a truncation in the protein are not shown. Reproduced with permission from our earlier publication [1].

Figure 4: ConSurf analysis of highly conserved amino acids in POR. Conserved regions are in yellow. The cutoff value is a score of $\geq 8$ using a ConSurf MSA.Pseudo $\Delta \Delta G$ is calculated for known SNPs in conserved regions using SDM. Predicted disease-causing SNPs are in red. 
Figure 5-Distribution of allele frequencies of the A503V variant of POR among different genetic groups.The A503V variant of POR (rs1057868) is most common (26.8\%) across all population groups. Analysis of genetic data from several large sequencing studies revealed many interesting differences. In the Caucasian and Hispanic populations, the A503V is present in $\sim 28 \%$ of all alleles. In Japanese (40\%) and Asian populations (34-39\%) the presence of 503V variant of POR is much higher. In the Pacific Islanders the A503V frequency is highest (48\%) while in the African populations the 503V allele has the lowest frequency and is present in only about $16 \%$ of all alleles. For each hierarchical level, pies represent relative frequencies. Super populations: EAS, East Asians. SAS, South Asians. EUR, Europeans. AMR, Ad Mixed Americans. AFR, Africans. Subpopulations: PAC, Pacific Islanders. JPT, Japanese in Tokyo, Japan. CHS Southern Han Chinese. CDX, Chinese Dai in Xishuangbanna, China. KHV, Kinh in Ho Chi Minh City, Vietnam. CHB, Han Chinese in Bejing. China. PJL, Punjabi from Lahore, Pakistan. ITU, Indian Telugu from the UK. GIH, Gujarati Indian from Houston, Texas. STU, Sri Lankan Tamil from the UK. BEB, Bengali from Bangladesh. FIN, Finnish in Finland. TSI, Toscani in Italia. IBS, Iberian Population in Spain. CEU, Utah Residents (CEPH) with Northern and Western Ancestry. GBR, British in England and Scotland. CLM, Colombians from Medellin, Colombia. MXL, Mexican Ancestry from Los Angeles USA. PUR, Puerto Ricans from Puerto Rico. PEL, Peruvians from Lima, Peru. ESN, Esan in Nigeria. ACB, African Caribbeans in Barbados. ASW, Americans of African Ancestry in SW USA. GWD, Gambian in Western Divisions in the Gambia. LWK, Luhya in Webuye, Kenya. MSL, Mende in Sierra Leone. YRI, Yoruba in Ibadan, Nigeria.

Figure 6: Population distribution of potentially disease causing variants. T93I seems to be a variant exclusive to South Asians. A172T seems to be most prevalent in Europeans. P284T seems to be a variant exclusive to Africans. T372M seems to be most prevalent in Americans. G537R seems to be a variant exclusive to Europeans. Y607C seems to be most prevalent in South Asians. 
Table 1: Patients with reports of POR deficiency.

\begin{tabular}{|c|c|c|c|c|c|c|}
\hline \multirow[b]{2}{*}{$\begin{array}{c}\text { Number } \\
\text { of Patients }\end{array}$} & \multirow[b]{2}{*}{$\begin{array}{c}\text { Chromosomal Sex } \\
46, \mathrm{XX} / 46, \mathrm{XY}\end{array}$} & \multirow[b]{2}{*}{$\begin{array}{c}\text { POR } \\
\text { Mutations }\end{array}$} & \multicolumn{3}{|c|}{ Phenotype } & \multirow[b]{2}{*}{ Reference } \\
\hline & & & $\begin{array}{c}\text { ABS } \\
\text { Features }\end{array}$ & $\begin{array}{l}\text { Abnormal } \\
\text { Genitalia }\end{array}$ & $\begin{array}{c}\text { Abnormal } \\
\text { Steroids }\end{array}$ & \\
\hline 4 & $2 / 2$ & $7 / 8^{*}$ & 3 & 3 & 4 & Flück 2004 [6] \\
\hline 3 & $2 / 1$ & $6 / 6$ & 1 & 2 & 3 & Arlt 2004 [56] \\
\hline 2 & $1 / 1$ & $4 / 4$ & 2 & 1 & 2 & Adachi 2004 [57] \\
\hline 1 & $0 / 1$ & $2 / 2$ & 1 & 0 & 1 & Wudy 2004 [111] \\
\hline $19\left(32^{\circ}\right)$ & $6^{\#} / 10^{\#}$ & $34 / 38^{*}$ & $19(32)$ & $12^{\#}$ & $10^{\#}$ & Huang 2005 [12] \\
\hline 10 & $6 / 4$ & $19 / 20^{*}$ & 9 & 9 & 10 & Fukami 2005 [59] \\
\hline 3 & $2 / 1$ & $6 / 6$ & 0 & 2 & 3 & Fukami 2006 [58] \\
\hline 7 & $2 / 5$ & $14 / 14$ & 5 & 2 & 7 & Homma 2006 [61] \\
\hline 1 & $1 / 0$ & $2 / 2$ & 1 & 1 & 1 & Williamson 2006 [112] \\
\hline 1 & $1 / 0$ & $1 / 2^{* \S 1}$ & 1 & 1 & 1 & Scott 2007 [64] \\
\hline 4 & $0 / 4$ & $8 / 8$ & 0 & 4 & 4 & Hershkovitz 2008 [113] \\
\hline 1 & $1 / 0$ & $2 / 2$ & 1 & 1 & 1 & Ko 2009 [34] \\
\hline $12\left(35^{\circ \circ}\right)$ & $7 / 5$ & $24 / 24$ & 11 & 11 & 12 & Fukami 2009 [60] \\
\hline 4 & $3 / 1$ & $8 / 8$ & 3 & 3 & 4 & Sahakitrungruang 2009 [63] \\
\hline 1 & $0 / 1$ & $2^{\S 2}$ & 0 & 1 & 1 & Idkowiak 2010 [31] \\
\hline 1 & $1 / 0$ & $2 / 2$ & 1 & 1 & 1 & But 2010 [35] \\
\hline 1 & $1 / 0$ & $2 / 2$ & 1 & 0 & 1 & Herkert 2011 [114] \\
\hline 7 & $5 / 2$ & $14 / 14$ & 7 & 5 & 7 & Idkowiak 2011 [62] \\
\hline 2 & $2 / 0$ & $4 / 4$ & 2 & 2 & 2 & Flück 2011 [13] \\
\hline 30 & $18 / 12$ & $54 / 60$ & 27 & 22 & $28^{\#}$ & Krone 2012 [29] \\
\hline 1 & $1 / 0$ & $2 / 2$ & 1 & 1 & 1 & Puiu 2012 [36] \\
\hline 1 & $1 / 0$ & $2 / 2$ & 1 & 1 & 1 & Guaragna-Filho 2012 [115] \\
\hline 1 & $0 / 1$ & $2 / 2$ & 0 & 1 & 1 & Sanchez-Garvin 2013 [116] \\
\hline 20 & $12 / 8$ & $39 / 40^{*}$ & 19 & 12 & & Reisch 2013 [117] \\
\hline 1 & - & $2 / 2$ & 1 & 1 & - & Oldani 2015 [118] \\
\hline 138 & $75 / 59$ & & $117(85 \%)$ & $99(72 \%)$ & & \\
\hline
\end{tabular}

*POR mutations not identified on all alleles.

${ }^{\circ} 19$ out of 32 patients with the ABS phenotype had POR mutations.

${ }^{\circ} 12$ out of 35 patients were new and other 23 cases were reported earlier.

\#Karyotype, description of genitalia or steroid profile not known for all patients.

${ }^{\S 1}$ Additional heterozygous mutations in CYP21B gene.

${ }^{\S 2}$ Additional heterozygote mutation Q798E in the androgen receptor gene. 
Table 2. Diagnostic ratios for PORD assessed by GC/MS from urine based on suggestions by Krone and Shackleton[29, 68]. Table reproduced with permission from our earlier publication $[1,2]$.

\begin{tabular}{ll}
\hline Enzyme activity & Diagnostic Ratio \\
\hline 21-Hydroxylase & $(17 \mathrm{HP}+\mathrm{PT}) /(\mathrm{THE}+\mathrm{THF}+5 \alpha \mathrm{THF})$ \\
21-Hydroxylase & $\mathrm{PTONE} /(\mathrm{THE}+\mathrm{THF}+5 \alpha \mathrm{THF})$ \\
P450 Oxidoreductase & $\mathrm{PD} /(\mathrm{THE}+\mathrm{THF}+5 \alpha \mathrm{THF})$ \\
P450 Oxidoreductase & $5 \mathrm{PD} /(\mathrm{THE}+\mathrm{THF}+5 \alpha \mathrm{THF})$ \\
$17 \alpha-$ Hydroxylase & $(\mathrm{THA}+5 \alpha \mathrm{THA}+\mathrm{THB}+5 \alpha \mathrm{THB}) /(\mathrm{THE}+\mathrm{THF}+5 \alpha \mathrm{THF})$ \\
17,20 Lyase & $(17 \mathrm{HP}+\mathrm{PT}) /(\mathrm{An}+\mathrm{Et})$ \\
\hline
\end{tabular}

17HP - 17OH-Pregnanolone (metabolite of 17OH-progesterone)

$\mathrm{PT}$ - Pregnanetriol (metabolite of $17 \mathrm{OH}$-progesterone)

THE - Tetrahydrocortisone (metabolite of cortisol and cortisone)

THF - Tetrahydrocortisol (metabolite of cortisol)

$5 \alpha \mathrm{THF}-$ (metabolite of cortisol)

PTONE - Pregnanetriolone (metabolite of 21-deoxycortisol)

PD - Pregnanediol (metabolite of progesterone, 11-deoxycorticosterone)

5PD - Pregnenediol (metabolite of pregnenolone)

THA - Tetrahydro-11-dehydrocorticosterone (metabolite of corticosterone)

$5 \alpha$ THA - (metabolite of corticosterone)

THB - Tetrahydrocorticosterone (metabolite of corticosterone)

$5 \alpha \mathrm{THB}$ - (metabolite of corticosterone)

An - Androsterone (metabolite of androstenedione, testosterone, $5 \alpha$-dihydrotestosterone and DHEA)

Et - Etiocholanolone (metabolite of testosterone and DHEA)

Note: Normal and standard values need to be established by each laboratory based on controls to specific methods for each steroid substrate and ratio. Rather than relying on individual values, a diagnosis based on ratios of the steroids described above will be more useful and neutralize some of the problems associated with exact measurement of steroids in different laboratories. 
Table 3.Influence of POR variantsfrom patients with PORD, on the enzyme activities of some redox partners of POR.

\begin{tabular}{|c|c|c|c|c|c|c|c|c|c|c|c|}
\hline POR & DBSNP id & $\begin{array}{l}\text { CYP } \\
\text { 3A4 }\end{array}$ & HO-1 & $\begin{array}{c}\text { CYP17 } \\
\text { A1 } \\
\text { 17OH- } \\
\text { ase }\end{array}$ & $\begin{array}{c}\text { CYP17A1 } \\
17,20 \\
\text { lyase }\end{array}$ & $\begin{array}{c}\text { CYP19A } \\
1\end{array}$ & $\begin{array}{l}\text { CYP } \\
1 A 2\end{array}$ & $\begin{array}{l}\text { CYP } \\
2 B 6\end{array}$ & $\begin{array}{l}\text { CYP } \\
2 \mathrm{C9}\end{array}$ & $\begin{array}{l}\text { CYP } \\
2 \text { C19 }\end{array}$ & $\begin{array}{l}\text { CYP } \\
\text { 2D6 }\end{array}$ \\
\hline WT & - & 100 & 100 & 100 & 100 & 100 & 100 & 100 & 100 & 100 & 100 \\
\hline p.T142A & - & 85 & 81 & 60 & 54 & - & 3 & & & - & \\
\hline p.Q153R & - & 119 & 72 & 31 & 27 & 189 & 144 & & 136 & 284 & 128 \\
\hline p.Y181D & rs72552771 & - & - & - & - & & - & 70 & & - & \\
\hline p.N185K & & & & - & - & & & & & & \\
\hline p.M263V & - & 119 & & 9 & 13 & & 92 & & & 136 & \\
\hline p.A287P & rs121912974 & 26 & 49 & 40 & 21 & 104 & - & 74 & 10 & - & - \\
\hline p.P339_E401del & - & & & 26 & 31 & & 30 & & & & \\
\hline p.R457H & rs28931608 & 10 & - & 3 & - & 1 & - & & 6 & - & - \\
\hline p.Y459H & - & - & - & 11 & - & - & - & & & - & \\
\hline p.V492E & rs28931606 & - & - & 3 & - & $<1$ & - & & & - & \\
\hline p.G539R & rs121912976 & 30 & & 46 & 8 & 12 & 10 & & & 33 & \\
\hline p.L565P & - & & & 32 & 19 & & - & & & - & \\
\hline p.C569Y & rs28931607 & 32 & 33 & 28 & 13 & 51 & 6 & & & - & \\
\hline p.L577R & & & & 46 & 27 & & & & & & \\
\hline p.Y607C & rs72557954 & & & 76 & 40 & 9 & 7 & & & 24 & \\
\hline p.V608F & rs72552772 & 16 & 32 & 80 & 57 & 24 & 5 & & & - & \\
\hline p.R616X & - & - & - & - & - & - & - & & & - & \\
\hline p.V631I & rs145782750 & 89 & 96 & 51 & 40 & 47 & 6 & & & 23 & \\
\hline p.delF646 & - & 88 & 95 & 97 & 46 & - & - & & & - & \\
\hline
\end{tabular}

Activities are shown as percentage of the wild-type POR. POR: P450 oxidoreductase. Data were compiled from previous studies [6, 8, 12-14, 25-27, 33, 91, 94, 98, 102-104, 119]. The V631I and Y607C were initially found in patients but later studies found these as population variants. Mutations listed in bold abolish all activity. These were found in patients with severe forms of disease and affected residues are located near co-factor binding sites of POR.

Enzymes/reactions and substrates (in parenthesis) listed in this table: CYP3A4: (BOMCC (7Benzyloxy-4-trifluoromethylcoumarin)); HO-1: Heme oxygenase-1 (heme); Cyt c red: Cytochrome c reduction (cytochrome c); NADPH ox: NADPH oxidation (NADPH); CYP17A1 17OH-ase: (Progesterone); CYP17A1 17,20 Lyase: (17-hydroxy Pregnenolone), CYP19A1: (androstenedione); CYP1A2, CYP2C19 and CYP2D6: (EOMCC ( 7-ethoxy-methyloxy-3cyanocoumarin). 
Table 4.Influence of POR variants found in normal population on the enzyme activities of its redox partners.

\begin{tabular}{|c|c|c|c|c|c|c|c|c|c|c|c|}
\hline POR & DBSNP id & $\begin{array}{c}\text { CYP } \\
\text { 3A4 }\end{array}$ & HO-1 & $\begin{array}{c}\text { CYP17A1 } \\
\text { 17OH-ase }\end{array}$ & $\begin{array}{c}\text { CYA1 } \\
\text { 17,20 } \\
\text { lyase }\end{array}$ & $\begin{array}{c}\text { CYP } \\
\text { 19A1 }\end{array}$ & $\begin{array}{c}\text { CYP } \\
\mathbf{1 A 2}\end{array}$ & $\begin{array}{c}\text { CYP } \\
\text { 2B6 }\end{array}$ & $\begin{array}{c}\text { CYP } \\
\text { 2C9 }\end{array}$ & $\begin{array}{c}\text { CYP } \\
\text { 2C19 }\end{array}$ & $\begin{array}{c}\text { CYP2 } \\
\text { D6 }\end{array}$ \\
\hline WT & - & 100 & 100 & 100 & 100 & 100 & 100 & 100 & 100 & 100 & 100 \\
\hline delE53 & rs72553987 & & & 73 & 82 & & 156 & & & 91 & \\
\hline P55L & rs72553988 & & & 82 & 115 & & 114 & & & 83 & \\
\hline A115V & rs199634961 & 85 & 95 & 80 & 71 & - & - & 93 & & - & \\
\hline D211N & rs72557914 & 107 & & 57 & 62 & & 52 & & & 52 & \\
\hline G213E & rs72557915 & & & 57 & 93 & & 174 & & & 101 & \\
\hline P228L & rs17853284 & 101 & 106 & 100 & 41 & 60 & 20 & & & 39 & \\
\hline P284T & rs72557937 & & & 14 & 19 & & - & & & - & \\
\hline P284L & rs72557938 & & & 44 & 82 & & 41 & & & 27 & \\
\hline E300K & rs11540674 & & & 112 & 146 & & 85 & & & & \\
\hline R316W & BV12016\# & 110 & 96 & 94 & 141 & 97 & 109 & & & 81 & \\
\hline R406H & rs72557929 & & & 61 & 57 & & 125 & & & 155 & \\
\hline G413S & BV12020\# & 100 & 104 & 83 & 110 & 105 & 73 & 81 & & 104 & \\
\hline P452L & rs72557935 & & & 48 & 61 & & 21 & & & 83 & \\
\hline A462T & rs72557936 & & & 58 & 66 & & 119 & & & 100 & \\
\hline V472M & rs72557946 & & & 58 & 46 & & 54 & & & 77 & \\
\hline A485T & rs72557947 & & & 68 & 88 & & 80 & & & 98 & \\
\hline A503V & rs1057868 & 107 & 97 & 68 & 58 & - & 85 & & 148 & 113 & 85 \\
\hline G504R & BV12031\# & 93 & 107 & 91 & 103 & 72 & 82 & & & 140 & - \\
\hline R600W & rs72557950 & & & 38 & 40 & & 36 & & & 60 & \\
\hline Y607C & rs72557954 & & & 76 & 40 & 9 & 7 & & & 24 & \\
\hline
\end{tabular}

Activities are shown as percentage of the wild-type POR. POR: P450 oxidoreductase. Data were compiled from previous reports [6, 8, 12-14, 25-27, 33, 91, 94, 98, 103]. \# DBSNP id not available, identified in a sequencing study by Bioventures Inc. [87] and are represented as Bioventure ID numbers BVxxxxx.

Enzymes/reactions and substrates (in parenthesis) listed in this table: CYP3A4: (BOMCC (7Benzyloxy-4-trifluoromethylcoumarin)); HO-1: Heme oxygenase-1 (heme); Cyt c red: Cytochrome c reduction (cytochrome c); NADPH ox: NADPH oxidation (NADPH); CYP17A1 17OH-ase: (Progesterone); CYP17A1 17,20 Lyase: (17-hydroxy Pregnenolone), CYP19A1:(androstenedione); CYP1A2,CYP2C19 and CYP2D6: (EOMCC ( 7-ethoxymethyloxy-3-cyanocoumarin). 
Table 5. POR A503V Allele Frequencies in Different Populations.

\begin{tabular}{|c|c|c|c|}
\hline Super population & Frequency & Subpopulation & Frequency \\
\hline \multirow[t]{6}{*}{ East Asians (EAS) } & 0.3912 & Pacific Islanders (PAC) & 0.4825 \\
\hline & & Japanese in Tokyo, Japan (JPT) & 0.4002 \\
\hline & & Southern Han Chinese (CHS) & 0.3952 \\
\hline & & Chinese Dai in Xishuangbanna, China (CDX) & 0.3656 \\
\hline & & Kinh in Ho Chi Minh City, Vietnam (KHV) & 0.3636 \\
\hline & & Han Chinese in Beijing, China (CHB) & 0.3398 \\
\hline \multirow{5}{*}{$\begin{array}{l}\text { South Asians } \\
\text { (SAS) }\end{array}$} & 0.3471 & Punjabi from Lahore, Pakistan (PJL) & 0.3750 \\
\hline & & Indian Telugu from the UK (ITU) & 0.3676 \\
\hline & & Gujarati Indian from Houston, Texas (GIH) & 0.3447 \\
\hline & & Sri Lankan Tamil from the UK (STU) & 0.3284 \\
\hline & & Bengali from Bangladesh (BEB) & 0.3198 \\
\hline \multirow[t]{5}{*}{ Europeans (EUR) } & 0.2883 & Finnish in Finland (FIN) & 0.3131 \\
\hline & & Toscani in Italia (TSI) & 0.3131 \\
\hline & & Iberian Population in Spain (IBS) & 0.2804 \\
\hline & & $\begin{array}{l}\text { Utah Residents (CEPH) with Northern and } \\
\text { Western Ancestry (CEU) }\end{array}$ & 0.2711 \\
\hline & & British in England and Scotland (GBR) & 0.2637 \\
\hline \multirow[t]{4}{*}{$\begin{array}{l}\text { Ad Mixed } \\
\text { Americans (AMX) }\end{array}$} & 0.2811 & $\begin{array}{l}\text { Colombians from Medellin, Colombia } \\
\text { (CLM) }\end{array}$ & 0.3457 \\
\hline & & $\begin{array}{l}\text { Mexican Ancestry from Los Angeles USA } \\
\text { (MXL) }\end{array}$ & 0.2967 \\
\hline & & Puerto Ricans from Puerto Rico (PUR) & 0.2452 \\
\hline & & Peruvians from Lima, Peru (PEL) & 0.2368 \\
\hline \multirow[t]{7}{*}{ Africans (AFR) } & 0.1588 & Esan in Nigeria (ESN) & 0.1970 \\
\hline & & African Caribbean in Barbados (ACB) & 0.1771 \\
\hline & & $\begin{array}{l}\text { Americans of African Ancestry in SW USA } \\
\text { (ASW) }\end{array}$ & 0.1723 \\
\hline & & $\begin{array}{l}\text { Gambian in Western Divisions in the Gambia } \\
\text { (GWD) }\end{array}$ & 0.1618 \\
\hline & & Luhya in Webuye, Kenya (LWK) & 0.1414 \\
\hline & & Mende in Sierra Leone (MSL) & 0.1412 \\
\hline & & Yoruba in Ibadan, Nigeria (YRI) & 0.1208 \\
\hline
\end{tabular}

Frequencies from 1000 Genomes [54], NHLBI Exome Sequencing Project (NHLBI Exome Sequencing Project, 2016), SNP500CANCER, POR-Miller [33], JBIC-allele [55] and EGP SNPs (NIEHS Environmental Genome Project, 2016) were collected and assigned to the categories of the 1000 Genomes project. Pacific Islanders (PAC) was created as a subcategory of East Asians (EAS). 

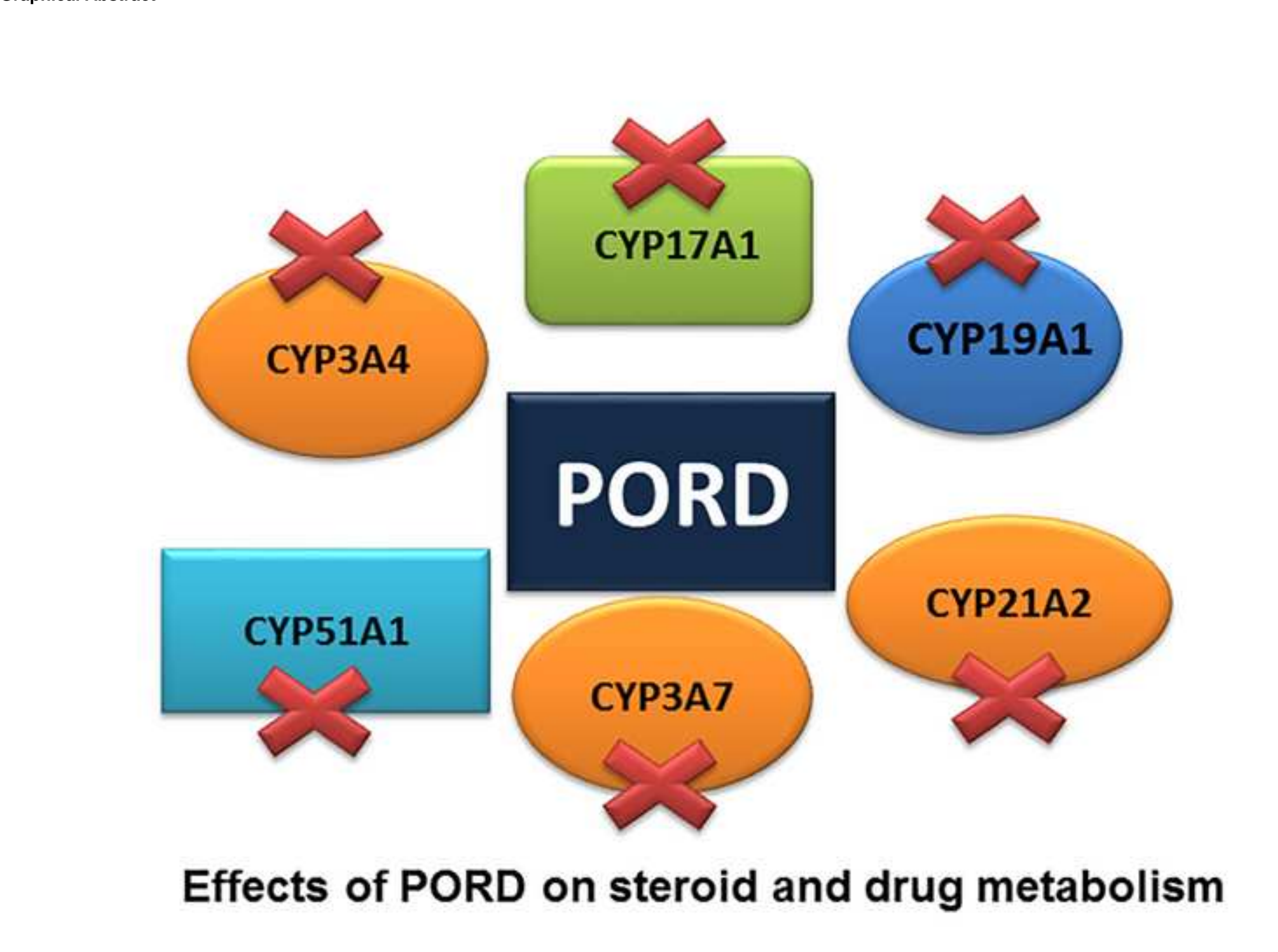

Effects of PORD on steroid and drug metabolism

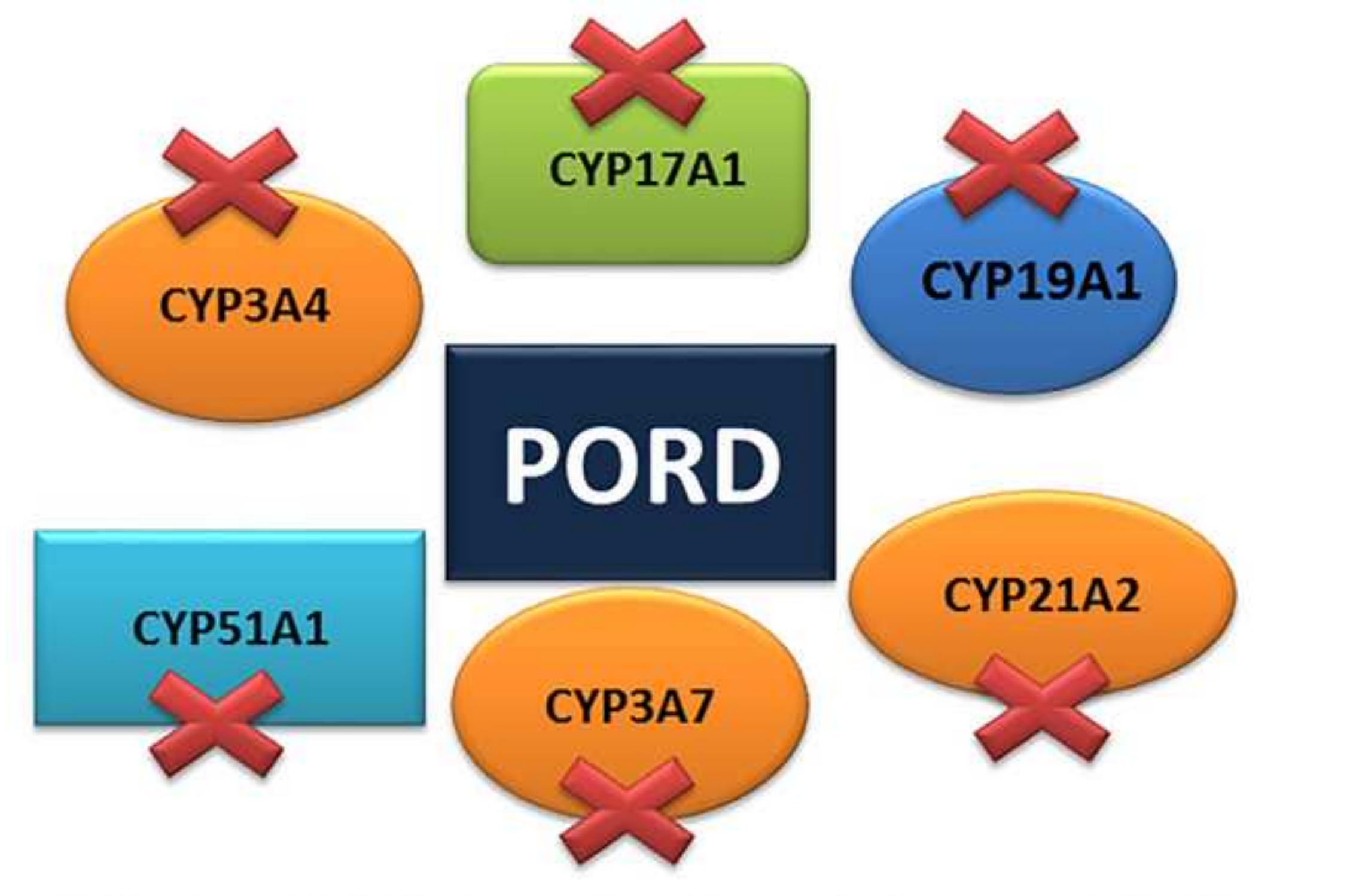

\title{
Effects of PORD on steroid and drug metabolism
}

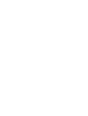

(

\begin{abstract}
.
\end{abstract}

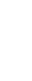

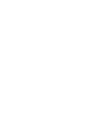

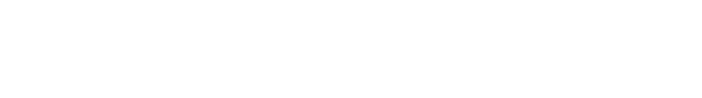




\section{Figure 1}

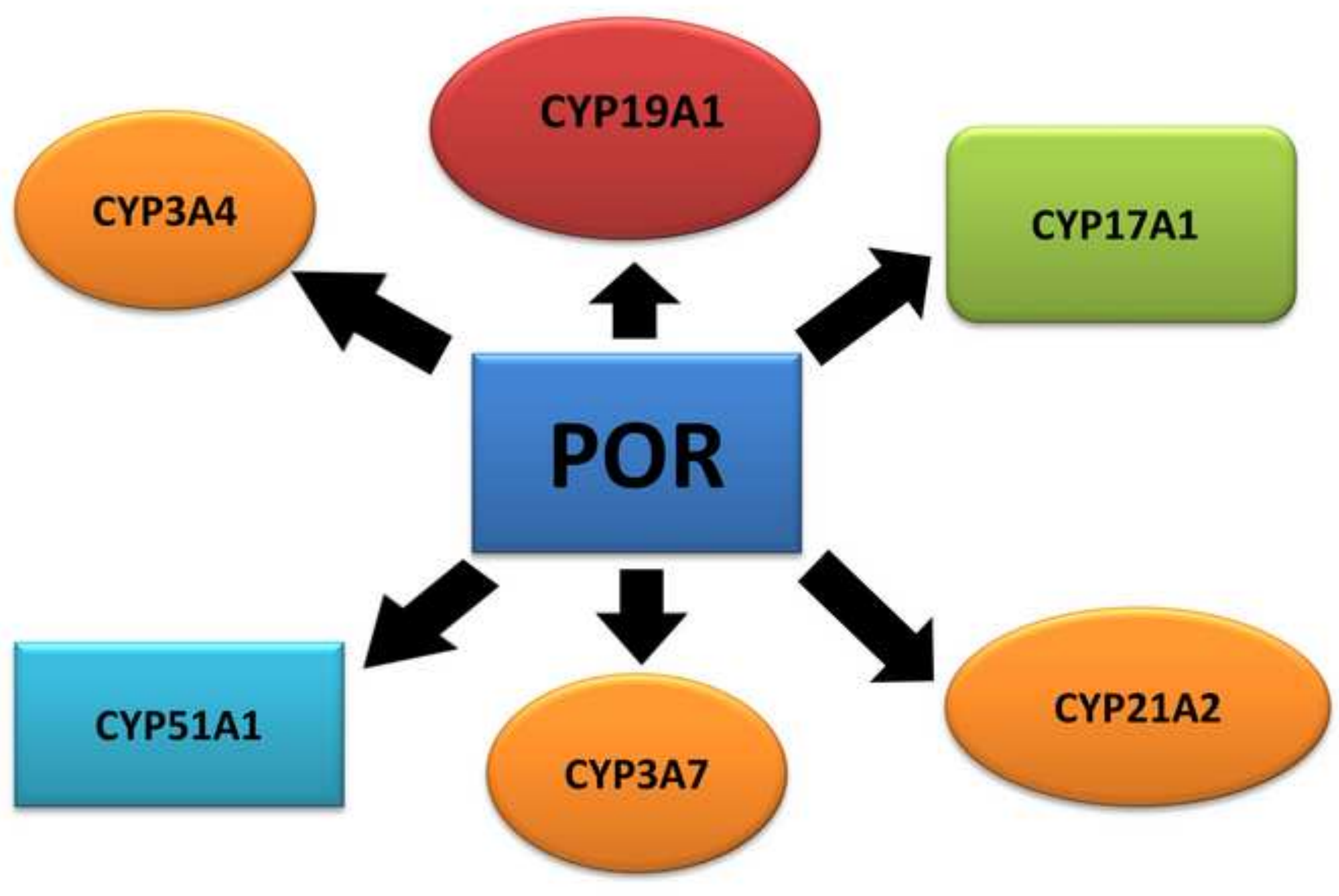




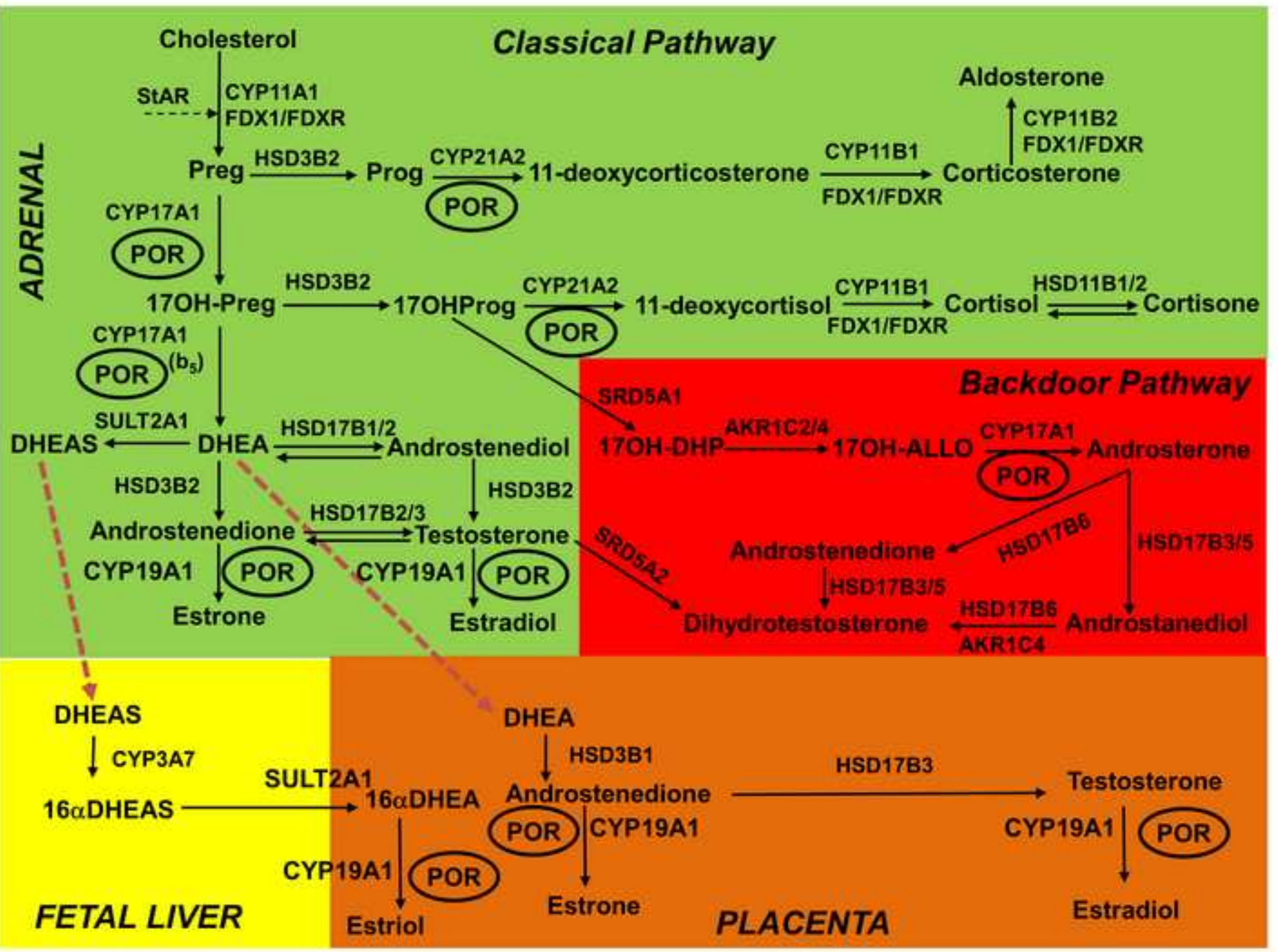




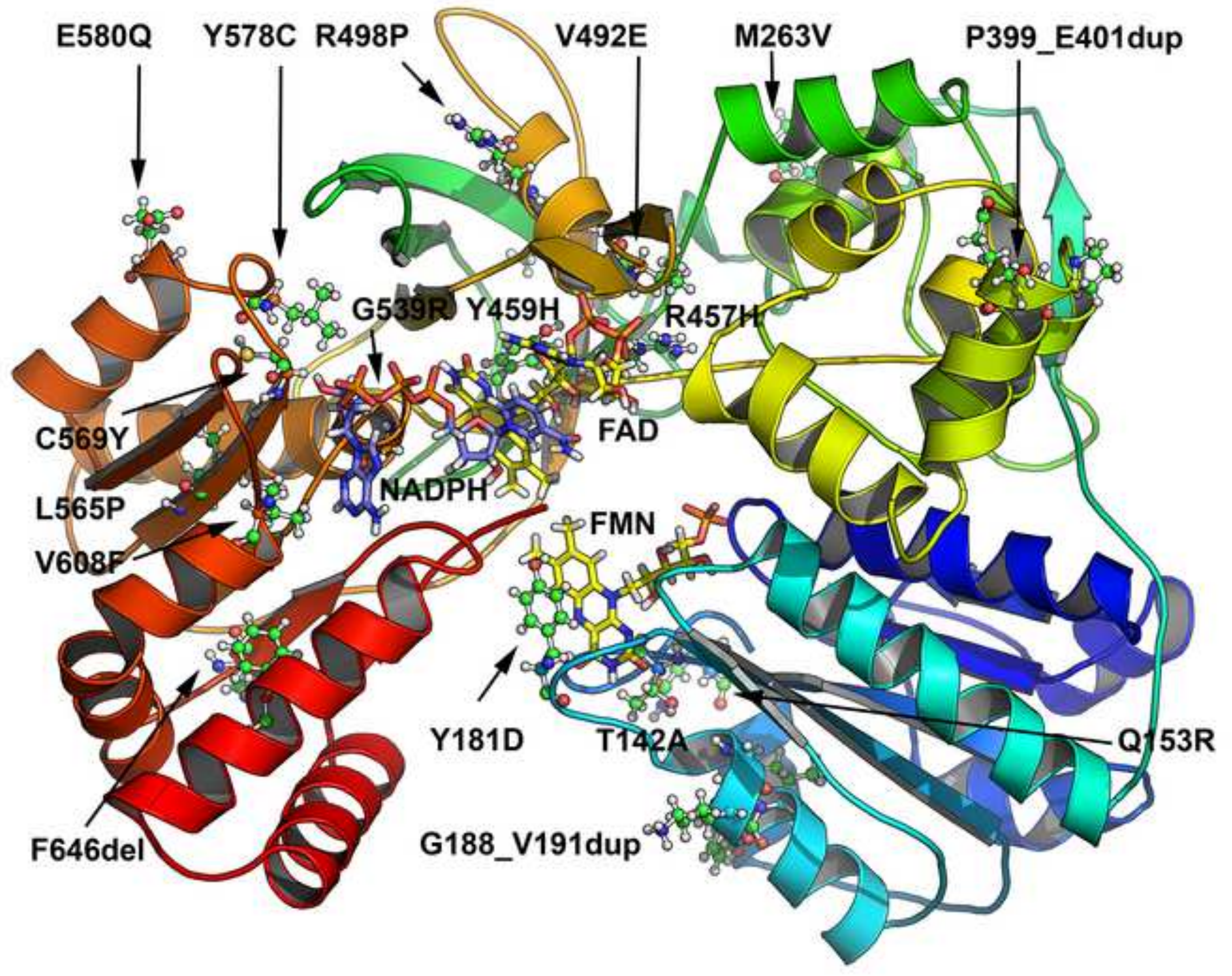




120

MINMGDSHVDTSSTVSEAVAEEVSLESMTDMILESLIVGLLTYWFLFRKKKEEVPEFTKIQTLTSSVRES

71

Bo

90

100

110

120

130

SFVEKMKKTGRNI IVEYGSQTGTAEEFANRLSKDAHRYGMRGMSADPEEYDLADLSSLPEIDNALVVFCM 141 150

160

170

180

190

200

ATYGEGDPTDNAQDFYDWLQETDVDLSGVKEAVEGLGNKTYEHFNAMGKYVDKRLEQLGAQRIFELGLGD
211
220
230
240
250
260
270

DDGNLEEDEITWREQFWPAVCEHFGVEATGEESSIRQYELVVHTDIDAAKVYMGEMGRLKSYENQKPPED $28123900320 \quad 390 \quad 330 \quad 340$ AKNPELAAVTTNRKLNQGTERHLMHLELDISDSKIRYESGDHVAVYPANDSALVNQLGKILGADLDVVMS 351 360

370

380

390

400

410

LNNLDEESNKKHPEPCPTSYRTALTYYLDITNPPRTNVLYELAQYASEPSEQELLRKMASSSGEGKELYL
421
430
440
450
460
470
4fí

SWVVEARRH I LAI I QDCPSLRPP I DHLCELLPRLQARYYS IASSSKVHPNSVH ICAVVVEYETKAGRINK $491500 \quad 510 \quad 520 \quad 530$

GVATNWLRAKEPAGENGGRALVPMEVRKSQFRLPEKATTPVIMVGPGTGVAPEIGEIQERAWLRQQGKEV 561 570

580

590

600

610

620

GETLLYYGCRRSDEDYLYREELAQFHRDGALTQLNVAFSREQSHKVYVQHLLKQDREHLWKLIEGGAHIY
631
640
650
560
670
ธิด

VCGDARNMARDVQNTEYDIVAELGAMEHAQAVDYIKKLMTKGRYSLDVWS 


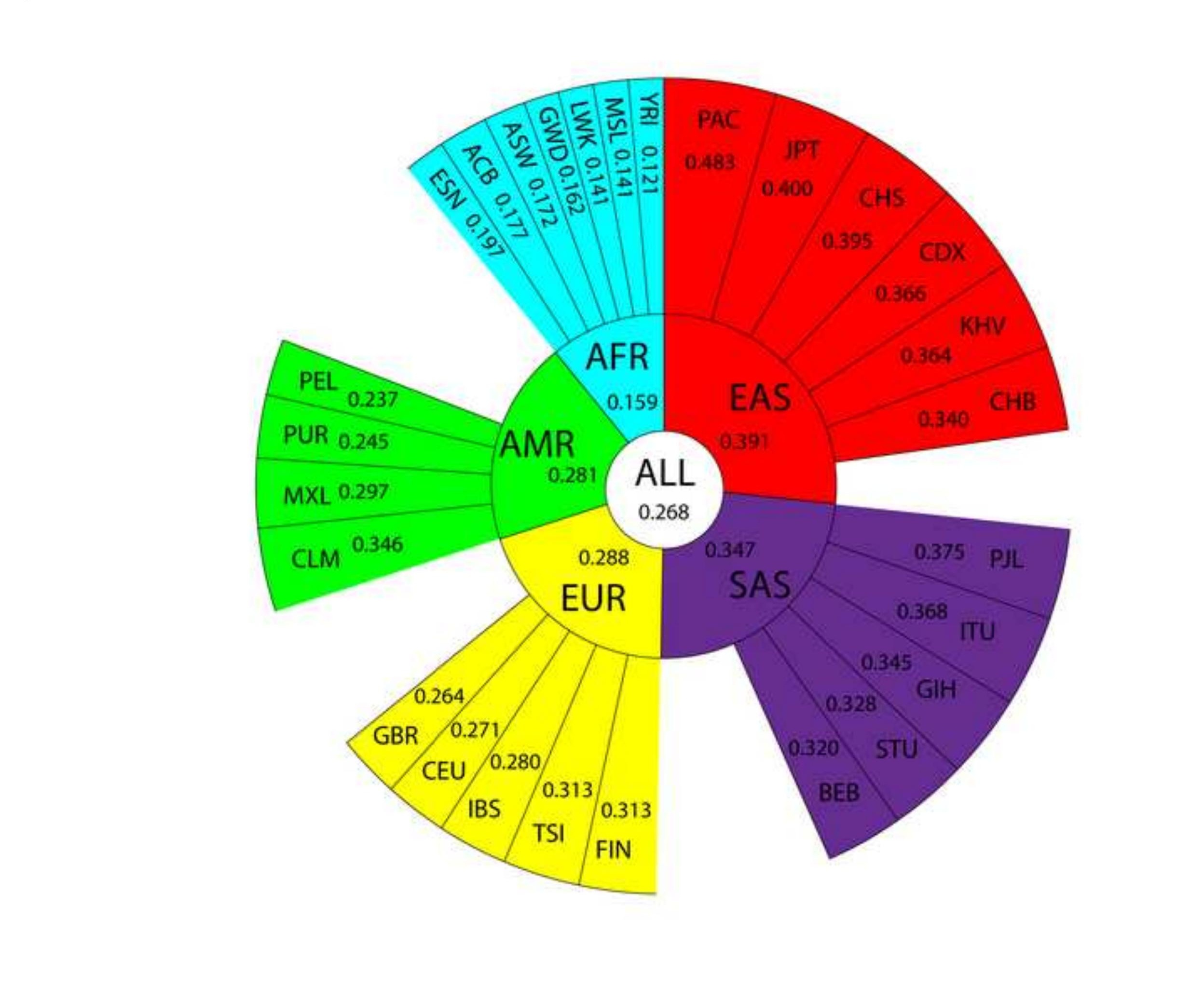

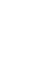
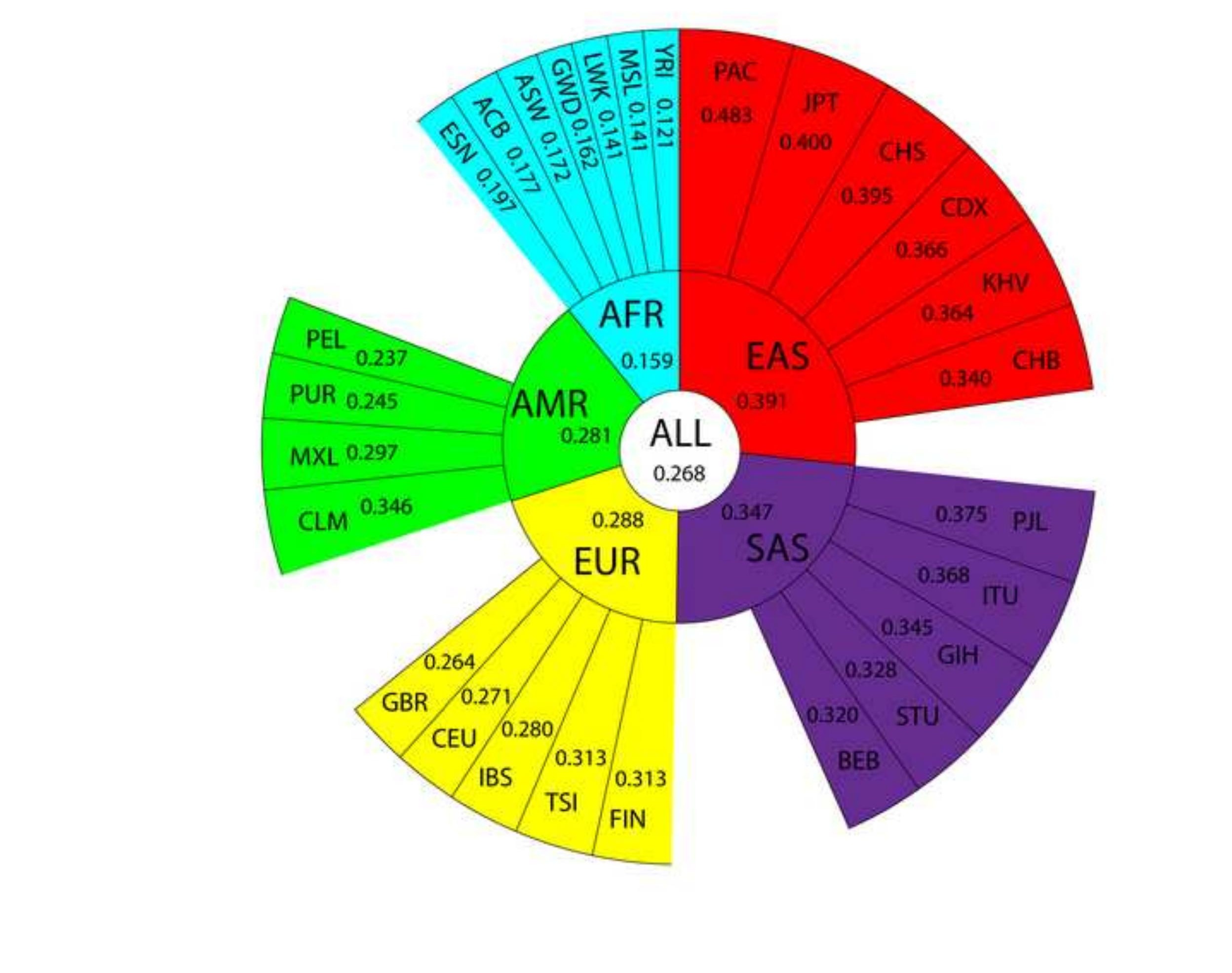

t

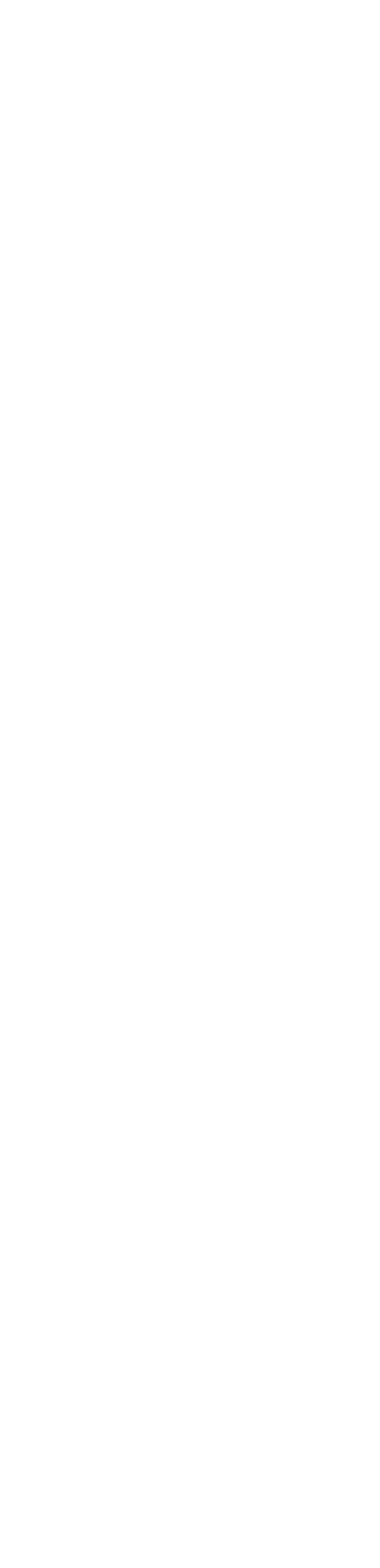

.

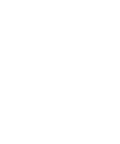

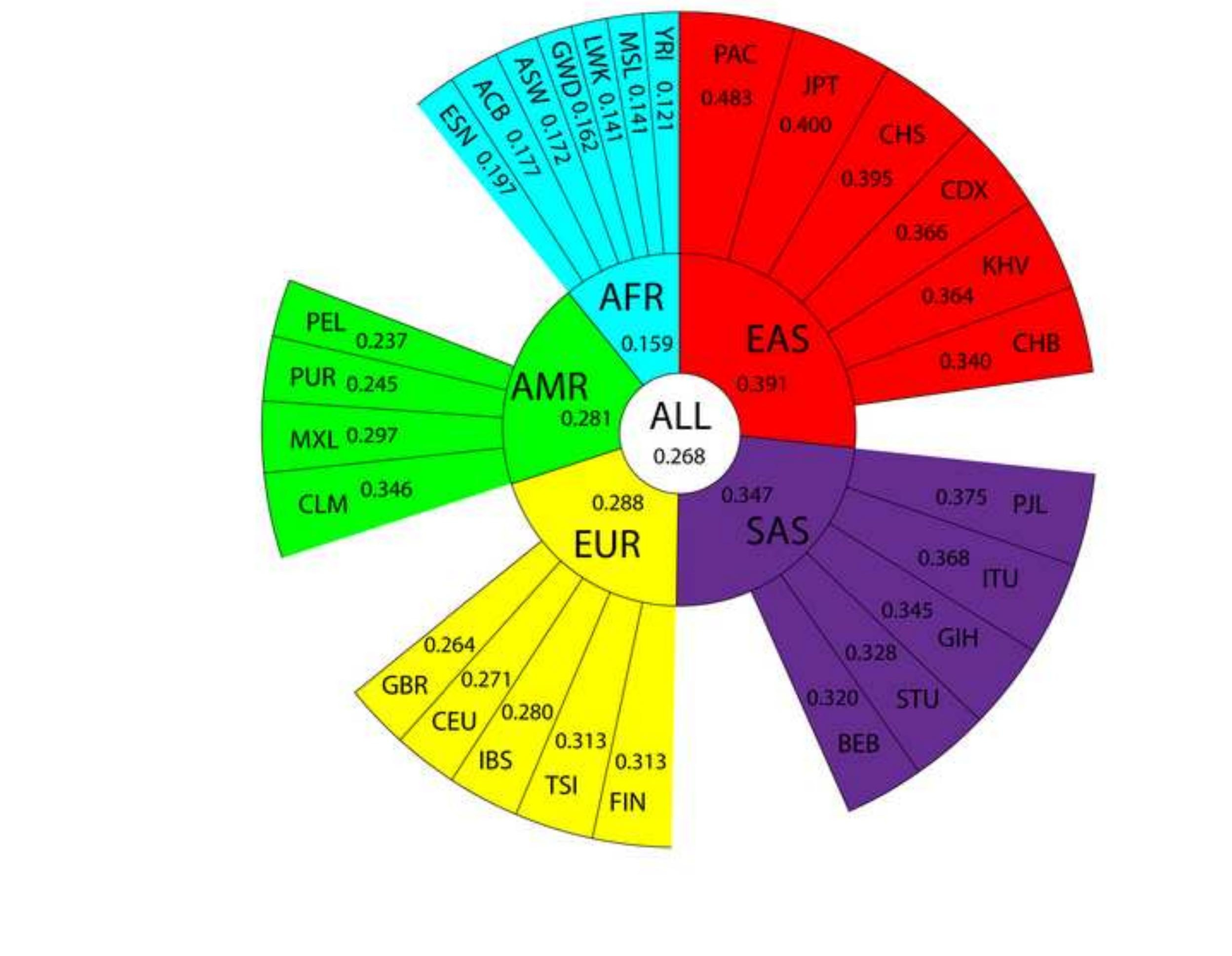

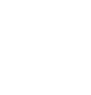




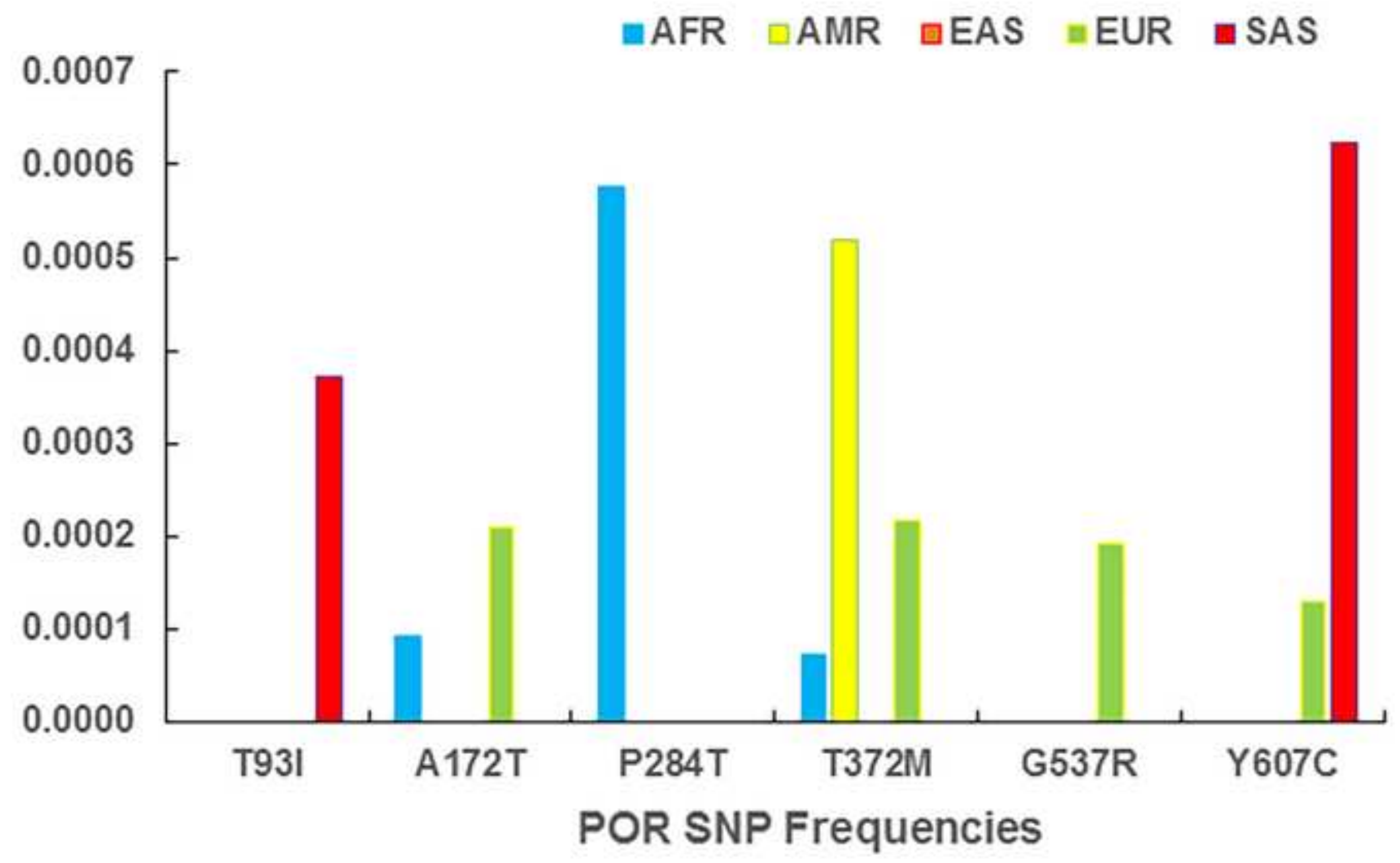

